\title{
Turnover Variances Analysis-Determinants for a Managerial and Competitive Analysis
}

\author{
Silvano Guelfi ${ }^{1} \&$ Paolo Saluto ${ }^{2}$ \\ ${ }^{1}$ Strategy \& Finance, Planning \& Control, Strategic Marketing, Department of Management and Production \\ Engineering, Politecnico di Torino, Torino, Italy \\ ${ }^{2}$ Department of Management and Production Engineering, Politecnico di Torino, Torino, Italy \\ Correspondence: Silvano Guelfi, Professor, Strategy \& Finance, Planning \& Control, Strategic Marketing, Director \\ of the research group Competitive Risk and Enterprise Value, Politecnico di Torino, Turin, 10129, Italy.
}

Received: January 12, 2019

Accepted: February 5, 2019

Online Published: February 27, 2019

doi:10.5430/ijba.v10n2p63

URL: https://doi.org/10.5430/ijba.v10n2p63

\begin{abstract}
The decision-making processes and the consequent managerial actions feed on timely knowledge. The analysis of variances is at the same time a logical process and a fundamental technique to know in real time the economic impact of the determinants of management performance and it drives actions in terms of skills, resources/processes, priorities.

This article, focused on the analysis of turnover variances highlights the differences between current and past performance as concerns volumes sold, mix of products sold, bonuses granted to customers and selling prices recognized by the customer, consists of two methodological sections:

1. Turnover Variances Analysis. From an algebraic difference to a managerial analysis: how much did impact the single determinants on the turnover change?

2. Benchmark Turnover Variances Analysis. From an internal to a competitive analysis: what was the company performance compared to the market one?
\end{abstract}

Keywords: variances analysis, competitive position, turnover variance

\section{Introduction}

Why current results are different from the past ones? or from the planned goals? Which are the determinants that contributed to strengthening or weakening business performance? What is the contribution of each single determinant to the overall result? What managerial information can be acquired through the determinants impact? To what extent and for what reasons are the company's performance better or worse than the market ones? Here are some of the questions that this article aims to answer through the variances analysis model (Anthony R.N, et al. 1999, Kaplan R.S. 1982, Hilton, et al. 2008) appropriately strengthened in some steps to allow the most accurate understanding of the company's performance and, therefore, the best orientation of decisions and managerial actions.

The starting point of the variances analysis is to choose the result configuration to analyze. The article focuses on the first essential magnitude for the company and for the related creation of economic value: the turnover. If it is true, as is true, that the creation of economic value (Porter M.E. 1979, Rappaport A. 1998, James L. Grant. 2003, Damodaran A. 2018) is the main objective of the company system, it is equally true that the starting point must be identified and the latter can only be the turnover ${ }^{1}$.

In detail, in addition to turnover and related marketing costs, there are six further fundamental managerial dimensions and related determinants (subject of future articles) to measure the company's ability to create economic value (figure 1, The Economic Value Variance Tree):

1. production costs, divided in direct materials, direct labor and overhead costs;

2. general and administrative costs;

3. fiscal costs;

4. cost of capital, function of operational risk, financial structure and interest rate structure; 
5. net capital employed, divided in net working capital and net fixed assets;

6. competitive advantage period.

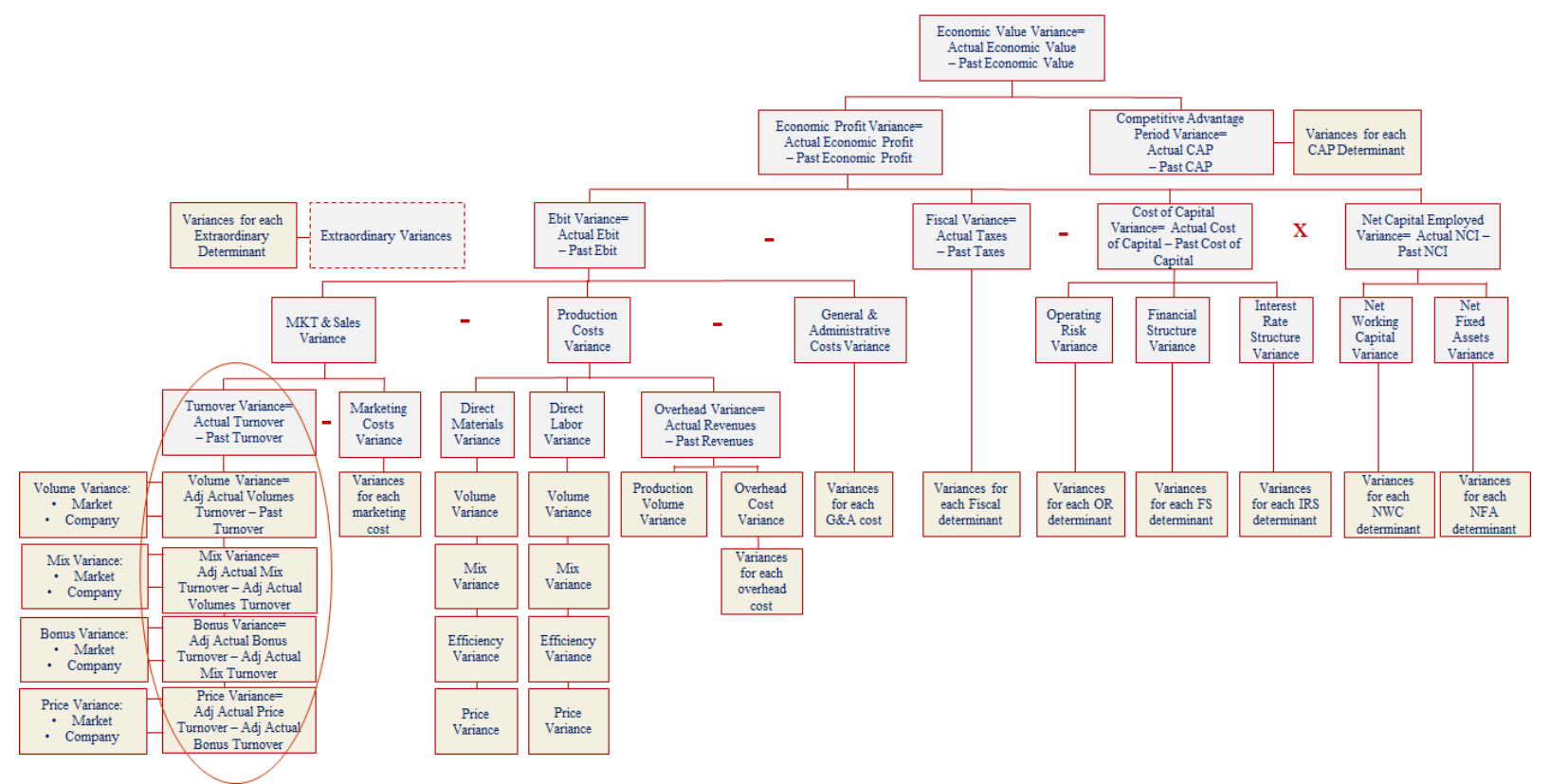

Figure 1. The economic value variance tree

The second step identifies the determinants that contribute to generate the selected result configuration, four for the present work:

1. volumes sold, i.e. how many units of output were sold;

2. mix of products sold, i.e. which units of output were sold;

3. bonuses recognized to customers in relation to the turnover achieved;

4. selling prices recognized by the customers.

The third step concerns how to order the aforementioned determinants according to the most significant managerial sequence, the so-called the right (compared to the information purpose) sequence. In this direction, the identified right sequence is the following:

1. volumes actually sold;

2. mix of the aforementioned volumes actually realized;

3. bonuses actually granted to customers on volumes and mixes realized;

4. prices of the actual volumes, mix and bonuses.

The fourth step compares the analysis of the turnover determinants of the company with those of the global market with the aim to measure distinctly the performance of the market from those of the company.

Before starting the technical development of the article, it is appropriate to highlight some keys to reading:

- the analysis of variances will be made for each single product of the company, for the company as a whole, and in comparative terms between the company and the global market;

- the current results are written in bold and the past ones in normal font;

- $\quad$ the letter $n$ indicates the $\mathrm{n}$-th product (both the company and the market);

- $\quad$ the letter $\mathrm{c}$ indicates the company and the letter $\mathrm{m}$ indicates the global market; 
- $\quad$ the letters V, B, P and M indicate respectively sold volumes, bonus percentage, unit price of the product and mix percentage of each product for the company, $\mathrm{Vc}, \mathrm{Bc}, \mathrm{Pc}$ and $\mathrm{Mc}$, and for the global market, $\mathrm{Vm}, \mathrm{Bm}, \mathrm{Pm}$ and $\mathrm{Mm}$;

- the methodological path, the development of the formulas and the numerical exemplification will be carried out analytically only for the product 1 while for the other products will be highlighted only the results.

The following tables 1 and 2 show the values of the turnover determinants respectively:

- for the company and for the related global market;

- $\quad$ for the past and actual performance.

Table 1. Company turnover determinants: past and actual product performance

\begin{tabular}{clrrrrrrrrrr}
\hline \multirow{2}{*}{ Sequence } & Company & \multicolumn{2}{c}{ Product 1 } & \multicolumn{2}{c}{ Product 2 } & \multicolumn{2}{c}{ Product 3 } & \multicolumn{2}{c}{ Product 4 } & \multicolumn{2}{c}{ Total } \\
& Determinants & \multicolumn{1}{c}{ Past } & Actual & \multicolumn{1}{c}{ Past } & Actual & Past & Actual & Past & Actual & Past & Actual \\
\hline A & Volumes (Vc) & 150 & 160 & 200 & 210 & 120 & 150 & 400 & 380 & 870 & 900 \\
B & Bonus & $2,50 \%$ & $3,00 \%$ & $6,00 \%$ & $5,00 \%$ & $4,00 \%$ & $4,60 \%$ & $3,00 \%$ & $3,60 \%$ & & \\
C & Percentage (Bc) & Unit Price (Pc) & 8,00 & 9,00 & 10,00 & 9,00 & 12,00 & 11,50 & 10,00 & 11,00 & \\
D & Mix (Mc) & $17,24 \%$ & $17,78 \%$ & $22,99 \%$ & $23,33 \%$ & $13,79 \%$ & $45,98 \%$ & $45,98 \%$ & $42,22 \%$ & 100,00 & 100,00 \\
E=A-C• & & $1.170,0$ & $1.396,8$ & $1.880,0$ & $1.795,5$ & $1.382,4$ & $1.645,6$ & $3.880,0$ & $4.029,5$ & $8.312,4$ & $8.867,4$ \\
$(1-\mathrm{B})$ & Turnover (Tc) & 0 & 0 & 0 & 0 & 0 & 5 & 0 & 2 & 0 & 7 \\
\hline
\end{tabular}

Table 2. Global market turnover determinants: past and actual product performance

\begin{tabular}{|c|c|c|c|c|c|c|c|c|c|c|c|}
\hline \multirow[b]{2}{*}{ Sequence } & \multirow{2}{*}{$\begin{array}{c}\text { Global } \\
\text { Market } \\
\text { Determinants }\end{array}$} & \multicolumn{2}{|c|}{ Product 1} & \multicolumn{2}{|c|}{ Product 2} & \multicolumn{2}{|c|}{ Product 3} & \multicolumn{2}{|c|}{ Product 4} & \multicolumn{2}{|c|}{ Total } \\
\hline & & Past & Actual & Past & Actual & Past & Actual & Past & Actual & Past & Actual \\
\hline A & $\begin{array}{l}\text { Volumes } \\
(\mathrm{Vm})\end{array}$ & 900 & 880 & 1.500 & 1.610 & 1.300 & 1.450 & 2.000 & 1.970 & 5.700 & 5.910 \\
\hline & Bonus & & & & & & & & & & \\
\hline B & $\begin{array}{l}\text { Percentage } \\
(\mathrm{Bm})\end{array}$ & $2,00 \%$ & $2,25 \%$ & $5,00 \%$ & $4,75 \%$ & $4,25 \%$ & $4,25 \%$ & $2,25 \%$ & $4,00 \%$ & & \\
\hline $\mathrm{C}$ & $\begin{array}{l}\text { Unit Price } \\
(\mathrm{Pm})\end{array}$ & 8,50 & 8,75 & 9,50 & 10,00 & 11,50 & 12,00 & 11,00 & 10,50 & & \\
\hline D & Mix (Mm) & $15,79 \%$ & $14,89 \%$ & $26,32 \%$ & $27,324 \%$ & $22,81 \%$ & $24,53 \%$ & $35,09 \%$ & $33,33 \%$ & $100,00 \%$ & $100,00 \%$ \\
\hline $\begin{array}{c}\mathrm{E}=\mathrm{A} \cdot \mathrm{C} \cdot \\
(1-\mathrm{B})\end{array}$ & $\begin{array}{l}\text { Turnover } \\
\text { (Tm) }\end{array}$ & $7.497,00$ & $7.526,75$ & $13.537,50$ & $15.335,25$ & $14.314,63$ & $16.660,25$ & $21.505,00$ & $19.857,60$ & $56.854,13$ & $59.380,30$ \\
\hline
\end{tabular}

\section{Turnover Variances Analysis: Methodological Sections}

The present article is divided in two methodological sections:

1. Turnover Variances Analysis. From an algebraic difference to a managerial analysis: the basic question to answer is: how much did impact the single determinants on the turnover change? (Donna G., et al. 2003, Gelman A. 2005)

2. Benchmark Turnover Variances Analysis. From an internal to a competitive analysis: the basic question to answer is: what was the company performance compared to the market one? (Bubbio A. 2009, Simons R. 2013)

The article ends with the application of the turnover variances analysis to the Italian Automotive Independent After Market sector, object of study since 2010 by the Research Centre Competitive Risk and Enterprise Value (CREV) of the Polytecnich University of Turin.

\subsection{Turnover Variances Analysis: From an Algebraic Difference to a Managerial Analysis}

The turnover is a set of several determinants and management needs to know exactly each specific impact on the turnover change. In particular, it is possible to carry out as many variances analysis as the identified turnover 
determinants. Consequently, if there are four turnover determinants, volumes, product mix, bonuses and prices, four turnover variances analysis can be carried out:

1. the volumes variance measures the impact of their change on turnover, maintaining product mix, bonuses and prices of the previous period;

2. the mix variance ${ }^{2}$ measures, as concerns the volumes actually realized, the impact of its change maintaining bonuses and prices of the previous period: it is not only important how much it is sold but what it is sold;

3. the bonuses variance ${ }^{3}$ measures, based on the volumes and the product mix actually realized, the impact of their change on turnover maintaining the prices of the previous period;

4. the prices variance measures, with volumes, product mix and bonuses actually realized, the impact of their change on turnover.

In operational terms and with reference to the 1 product of the company:

a. 1 Actual Turnover is equal to the multiplication of four actual company determinants: volumes ( $\mathbf{V c}), 1 \mathrm{mix}$ (Mc1), 1 price (Pc1) and 1 percentage bonus (Bc1);

b. $\quad 1$ Past Turnover is equal to the multiplication of the same four determinants in the past: volumes $(\mathrm{Vc}), 1 \mathrm{mix}$ $(\mathrm{Mc} 1), 1$ price $(\mathrm{Pc} 1)$ and 1 percentage bonus $(\mathrm{Bc} 1)$;

c. to obtain the 1 Company Turnover Variance $1 \mathrm{CVT}$ it's sufficient to properly compose the above actual and past values of the determinants. The variances analysis is carried out through the "shifting" and the "difference" model:

c1. the "shifting" model begins from the past turnover, modifies the turnover by replacing a determinant at a time in according to the right sequence and then make the difference between the adjusted actual turnover and the previous one. For example, the 1 company volume variance is equal to the difference between the " 1 adjusted actual volumes turnover", because actual company volumes replace past company volumes, and the "past turnover".

1 Company Turnover Variances Analysis through four Determinants. The "shifting" model formula:

$$
\begin{aligned}
& 1 \text { Company Turnover Variance CTV=1 Actual Turnover }-1 \text { Past Turnover= } \\
& \text { Vc } \times \text { Mc1 } \times \text { Pc1 } x(1-\text { Bc1) - Vc } \times \text { Mc1 } x \text { Pc1 } x(1-B c 1)= \\
& 900 \times 17,78 \% \times 9,00 \times(1-3,00 \%)-870 \times 17,24 \% \times 8,00 \times(1-2,50 \%)=226,80
\end{aligned}
$$

Shift Vc with Ve:

$$
\begin{gathered}
1 \text { Company Volume Variance CVT=1 Adjusted Actual Volumes Turnover - } n \text { Past Turnover= } \\
\text { Vc } \times M c 1 \times P c 1 \times(1-B c 1)-V c \times M c 1 \times P c 1 \times(1-B c 1)= \\
900 \times 17,24 \% \times 8,00 \times(1-2,50 \%)-870 \times 17,24 \% \times 8,00 \times(1-2,50 \%)=1.210,34-1.170,00=40,34
\end{gathered}
$$

Shift Mc1 with Mc1:

1 Company Mix Variance CMV=1 Adjusted Actual Mix Turnover - 1 Adjusted Actual Volumes Turnover=

$$
\text { Vc } x \text { Mc1 } x \text { Pcl } x(1-B c 1)-V c x M c 1 \times P c 1 \times(1-B c 1)=
$$

$900 \times \mathbf{1 7 , 7 8 \%} \times 8,00 \times(1-2,50 \%)-900 \times 17,24 \% \times 8,00 \times(1-2,50 \%)=1.248,00-1.210,34=37,66$

Shift Bc1 with Bc1

1 Company Bonus Variance CBV=1 Adjusted Actual Bonus Turnover -1 Adjusted Actual Mix Turnover=

$$
\text { Vc } x \text { Mc1 } x \text { Pc1 } x(1-\boldsymbol{B c 1})-V c \times \text { Mc1 } x \text { Pc1 } x(1-B c 1)=
$$

$900 \times \mathbf{1 7 , 7 8 \%} \times 8,00 \times(1-\mathbf{3 , 0 0 \%})-\mathbf{9 0 0} \times \mathbf{1 7 , 7 8 \%} \times 8,00 \times(1-2,50 \%)=1.241,60-1.248,00=-6,40$

Shift Pc1 with Pc1

1 Company Price Variance CPV=1 Adjusted Actual Price Turnover - 1 Adjusted Actual Bonus Turnover=

$$
\text { Vc } x \text { Mc1 } x \text { Pc1 } x(1-B c 1)-V c \times \text { Mc1 } x \text { Pc1 } x(1-B c 1)=
$$

$900 \times \mathbf{1 7 , 7 8 \%} \times \mathbf{9 , 0 0} \times(1-3,00 \%)-900 \times \mathbf{1 7 , 7 8 \%} \times 8,00 \times(1-3,00 \%)=1.396,80-1.241,60=155,20$

Total:

$$
\begin{gathered}
1 \text { Company Turnover Variance } C T V=\sum 4 \text { single determinants }=C V T+C M V+C B V+C P V=(6) \\
40,34+37,66-6,40+155,20=226,80
\end{gathered}
$$


c2. the "difference" model stresses, in according to the right sequence and always in according to the progressive replacement of each determinant, the difference between the actual and past value of each determinant and multiply it for the other determinants. For example, the 1 company volume variance is equal to the difference between actual and past company volumes multiplied for the past values of the other determinants, Mc1, Pc1 and $(1-\mathrm{Bc} 1)$.

1 Company Turnover Variances through four Determinants. The "difference" model formula:

Difference between $\mathbf{V c}$ and $\mathrm{Vc}$

$$
1 \text { Company Volume Variance CVT= Difference } 1 \text { Actual and Past Volumes= }
$$

$$
(\boldsymbol{V c}-V c) \times M c 1 \times P c 1 \times(1-B c 1)=(\mathbf{9 0 0}-870) \times 17,24 \% \times 8,00 \times(1-2,50 \%)=40,34
$$

Difference between Mc1 and Mc1:

$$
\begin{gathered}
1 \text { Company Mix Variance CMV= Difference } 1 \text { Actual and Past Mix= } \\
\text { Vc } \times(\mathbf{M c 1}-\text { Mc1 }) \times \text { Pc1 } \times(1-B c 1)=\mathbf{9 0 0} \times(\mathbf{1 7 , 7 8 \%}-17,24 \%) \times 8,00 \times(1-2,50 \%)=37,66
\end{gathered}
$$

Difference between $\mathrm{Bc} 1$ and $\mathrm{Bc} 1$ :

$$
\begin{aligned}
& 1 \text { Company Bonus Variance CBV= Difference } 1 \text { Actual and Past Bonus } \\
& \text { Vc } \times \mathbf{M c 1} \times \text { Pcl } \times(B c 1-B \boldsymbol{c 1})=\mathbf{9 0 0} \times \mathbf{1 7 , 7 8 \%} \times 8,00 \times(2,50 \%-\mathbf{3 , 0 0 \%})=-6,40
\end{aligned}
$$

Difference between Pc1 and Pc1:

$$
\begin{gathered}
1 \text { Company Price Variance CPV= Difference } 1 \text { Actual and Past Price }= \\
\operatorname{Vc} \times \mathbf{M c 1} \times(\mathbf{P c 1}-\mathrm{Pc1}) \times(1-\mathbf{B c 1})=\mathbf{9 0 0} \times \mathbf{1 7 , 7 8 \%} \times(\mathbf{9 , 0 0}-8,00) \times(1-\mathbf{3 , 0 0 \%})=155,20
\end{gathered}
$$

Total:

$$
\begin{gathered}
1 \text { Company Turnover Variance } C T V=\sum 4 \text { single variances }=C V T+C M V+C B V+C P V= \\
40,34+37,66-6,40+155,20=226,80
\end{gathered}
$$

In short, the 1 company turnover variances are generated by four variances:

a. the positive company volume variance due to higher volumes sold by the company, Vc $>$ Vc, $900>870$, generates an higher turnover of $+40,34$;

b. the positive 1 company mix variance due to a greater incidence of the product 1 (compared to the other products), Mc1 > Mc1, 17,78\% > 17,24\%, generates an higher turnover of +37,66;

c. the negative 1 company bonus variance due to a greater bonus recognized to the customers of the product 1 , Bc1 > Bc1, 3,00\% > 2,50\%, generates a lower turnover of $-6,40$;

d. the positive 1 company price variance due to a higher selling price recognized by the customers of the product 1 , Pc1 > Pc1, 9,00 > 8,00, generates an higher turnover of $+155,20$.

From a managerial point of view, the 1 company turnover variances are very rich of business meanings:

a. the positive change of 226,80 is explained for 155,20 , or $70 \%$, by prices increase;

b. the negative contribution related to the greater customer bonus, $-6,40$, is more than offset by prices increase, $+155,20$;

c. the positive change in product 1 is significantly influenced, $+40,34$, by the increase in total company volumes;

d. the so-called mix effect, related to the higher increase of the product 1 incidence on the total volumes sold, has generated a positive contribution equal to $+37,66$.

There are two interesting ways to represents graphically the transition from the 1 past turnover to the current one:

1. the bridge chart (figure 2) explains, using the histogram bars, the passage fromt the past turnover to the current turnover through the positive or negative contribution of the various turnover determinants; 


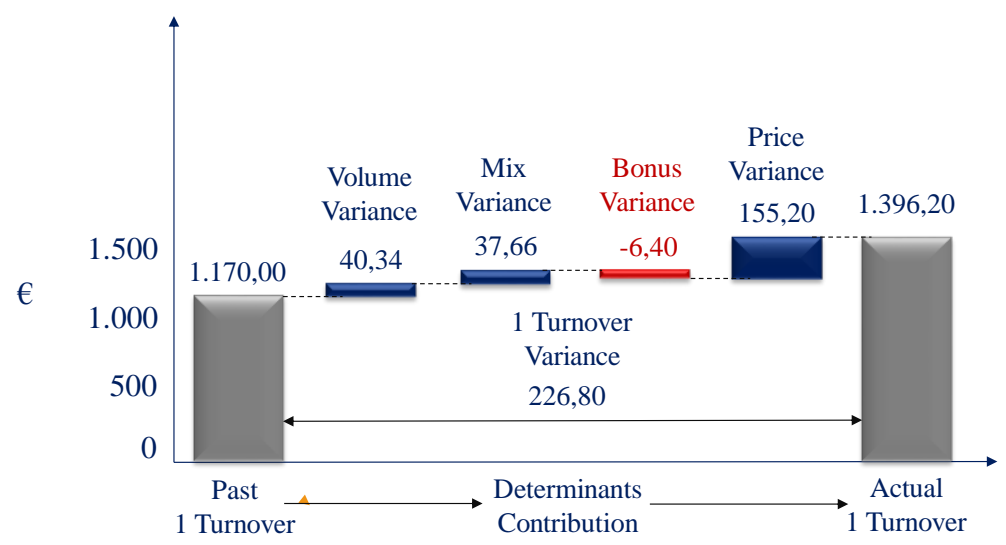

Figure 2. 1 Company turnover variances: the bridge chart

2. the compression/expansion chart extends or reduces the size of the past turnover operating on the $x$-axis, through volumes and mix determinants, and on the y-axis, through bonuses and prices determinants: there are three compression/extension areas (figure 3):

a. the revenues generated or absorbed by the change in volumes and mix considering the past net prices (bonuses included): it's the so called quantity (volumes+mix) effect: (Vc x Mc1 - Vc x Mc1) x Pc1 x $(1-\mathrm{Bc} 1)=(\mathbf{9 0 0} \times \mathbf{1 7 , 1 8 \%}-870 \times 17,24 \%) \times 7,80=78,00$; the above amount coincides with the sum of the volumes and mix variances (respectively 40,34 and 37,66 );

b. the revenues generated or absorbed by the net price change (bonuses included) in relation to past volumes and mix: it's the so called net price on old quantity effect: (Pc1 x (1-Bc1) - Pc1 x (1-Bc1)) x Vc x Mc1= $(\mathbf{8 , 7 3}-7,80) \times 870 \times 17,24 \%=139,50$; this amount is the first part of the net price variance (price variance $+155,20+$ bonus variance $-6,40=148,80$ );

c. the change in net prices (bonuses included) related to the change in volumes and mix: this joint area is not usely reported separately but generally is included in the price variance: $(\mathbf{P c 1} \times(1-\mathbf{B c 1})-\mathrm{Pc} 1 \times \mathrm{x}(1-\mathrm{Bc} 1)-$ $($ Vc x Mc1 - Vc x Mc1 $)=(\mathbf{8 , 7 3 - 7 , 8 0 )}$ x $(\mathbf{9 0 0} \times \mathbf{1 7 , 7 8 \%}-870 \times 17,24)=9,30$. This amount is the second part of the net price variance (adding 139,50, first part of the net price variance, and $+9,30$, second part of the net price variance, we obtain the net price variance, 148,80).

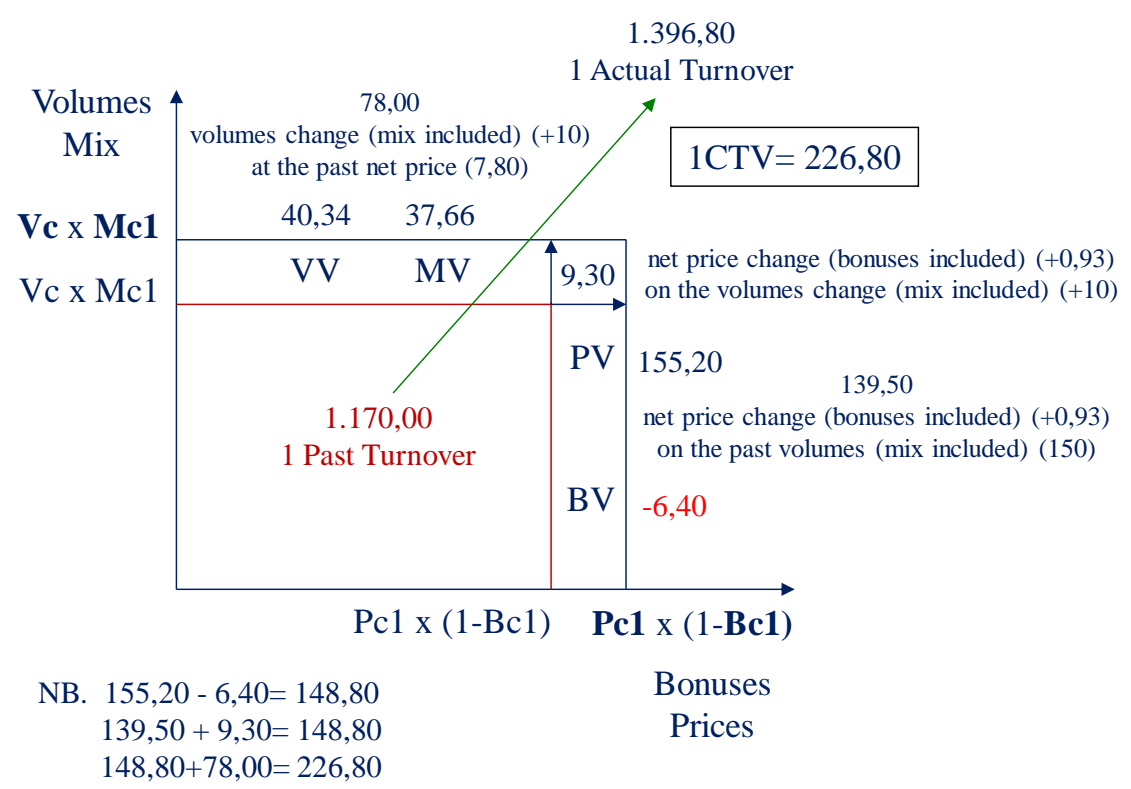

Figure 3. 1 Company turnover variances: the 1 compression expansion chart 
To obtain the company turnover variance, CTV, it is sufficient to add up the $n$ company turnover variances: CTV= $1 \mathrm{CVT}+2 \mathrm{CVT}+3 \mathrm{CVT}+4 \mathrm{CVT}$ (table 3 ). It' very interesting to highlight:

a. the positive company turnover variance equal to $+555,07,+6,68 \%$ compared to the past turnover of $8.312,40$;

b. the positive relationship between the bonuses sacrifice, $-19,00$, and the volumes/mix answer, $+286,63$ and $+36,97$, and despite the prices increase, $+250,47$ : respectively $+3,45 \%,+0,44 \%$ and $+3,01 \%$ compared to the past turnover of $8.312,40$;

c. the negative turnover contribution related to the product $2,-84,50(-1,02 \%)$, caused by the negative price effect, $-199,50(-2,40 \%)$, not offset by the positive variance of volumes/mix, $+94,00(+1,13 \%)$, and bonuses, $+21,00$ $(+0,25 \%)$;

d. the positive turnover variance of the product 3 thanks to the mix improvement, $+297,93(+3,58 \%)$, probably supported by prices and bonuses sacrifice;

e. the positive turnover variance of the product 1 is driven by the price variance, $+155,20(+1,87 \%)$, and from the simultaneous positive variance of volumes, $+40,34(+0,49 \%)$, and mix $,+37,66(+0,45 \%)$;

f. the fourth product highlights a positive balance, $+149,52(+1,80 \%)$, between the price variance, $+366,32$ $(+4,41 \%)$, and the volume/mix variance, $-194,00(-2,33 \%)$.

Table 3. Company turnover variances as sum of volumes, mix, bonuses and prices company turnover variances (in italic the percentage change related to the past company turnover of $8.312,40$ )

\begin{tabular}{cccccc}
\hline $\begin{array}{c}\text { Company Turnover } \\
\text { Variances }\end{array}$ & Product 1 & Product 2 & Product 3 & Product 4 & Total \\
\hline Company Volumes & 40,34 & 64,83 & 47,67 & 133,79 & 286,63 \\
Variance & $(0,49 \%)$ & $(0,78 \%)$ & $(0,57 \%)$ & $(1,61 \%)$ & $(+3,45 \%)$ \\
Company & 37,66 & 29,17 & 297,93 & $-327,79$ & 36,97 \\
Mix Variance & $(0,45 \%)$ & $(0,35 \%)$ & $(+3,58 \%)$ & $(-3,94 \%)$ & $(+0,44 \%)$ \\
Company Bonus & $-6,40$ & 21,00 & $-10,80$ & $-22,80$ & $-19,00$ \\
Variance & $(-0,08 \%)$ & $(0,25 \%)$ & $(-0,13 \%)$ & $(-0,27 \%)$ & $(-0,23 \%)$ \\
Company Price & 155,20 & $-199,50$ & $-71,55$ & 366,32 & 250,47 \\
Variance & $(1,87 \%)$ & $(-2,40 \%)$ & $(-0,86 \%)$ & $(4,41 \%)$ & $(+3,01 \%)$ \\
Company Turnover & 226,80 & $-84,50$ & 263,25 & 149,52 & 555,07 \\
Variance & $(2,73 \%)$ & $(-1,02 \%)$ & $(3,17 \%)$ & $(1,80 \%)$ & $(+6,68 \%)$ \\
\hline
\end{tabular}

To improve understanding the company's turnover performance it is appropriate to normalize, set equal to 100 the company turnover variance, the different contributions of each determinant (table 4):

a. the mix variance of the fourth product has given the worst contribution to the company turnover dynamic consuming $59,1 \%$ of the total turnover increase;

b. the product 2 is the worst performer, $-15,2 \%$ of the total turnover increase, and all the negativity is attributable to the price dynamics, $-35,9 \%$;

c. the bonus determinant is the only one with a negative contribution, except product 2 , but it must be evaluated in according to the effects on volumes/mix and in relation to the price decisions;

d. the increase of the product 4 prices generated the $66,0 \%$ of the total turnover increase, in turn partially consumed by the negative contribution of volumes/mix, $-35,00 \%$;

e. the product 3 highlights a positive relationship between price turnover variance, $-12,9 \%$ of the total turnover increase, and volume/mix turnover variance, $62,3 \%$;

f. the product 4 improves in all turnover variances except a slight compression due to higher bonuses, but the total turnover variance is very positive and explains the $40,9 \%$ of the global company turnover increase. 
Table 4. Company turnover variance as sum of $n$ company turnover variances

\begin{tabular}{cccccc}
\hline Variances & 1 & 2 & 3 & 4 & Total \\
\hline$n$ Company Volumes Variance & $7,3 \%$ & $11,7 \%$ & $8,6 \%$ & $24,1 \%$ & $51,6 \%$ \\
$n$ Company Mix Variance & $6,8 \%$ & $5,3 \%$ & $53,7 \%$ & $-59,1 \%$ & $6,7 \%$ \\
$n$ Company Bonus Variance & $-1,2 \%$ & $3,8 \%$ & $-1,9 \%$ & $-4,1 \%$ & $-3,4 \%$ \\
$n$ Company Price Variance & $28,0 \%$ & $-35,9 \%$ & $-12,9 \%$ & $66,0 \%$ & $45,1 \%$ \\
Company Turnover Variance & $40,9 \%$ & $-15,2 \%$ & $47,4 \%$ & $26,9 \%$ & $100,0 \%$ \\
\hline
\end{tabular}

Also for the company as a whole is interesting the bridge graph to make immediately visible the contribution of each determinant to the passage between past and current company turnover (Figure 4): volume variance, $+286,63$, mix variance, $+36,97$, bonus variance, $-19,00$ and price variance, 250,47 for a positive company turnover variance of $+555,07$.

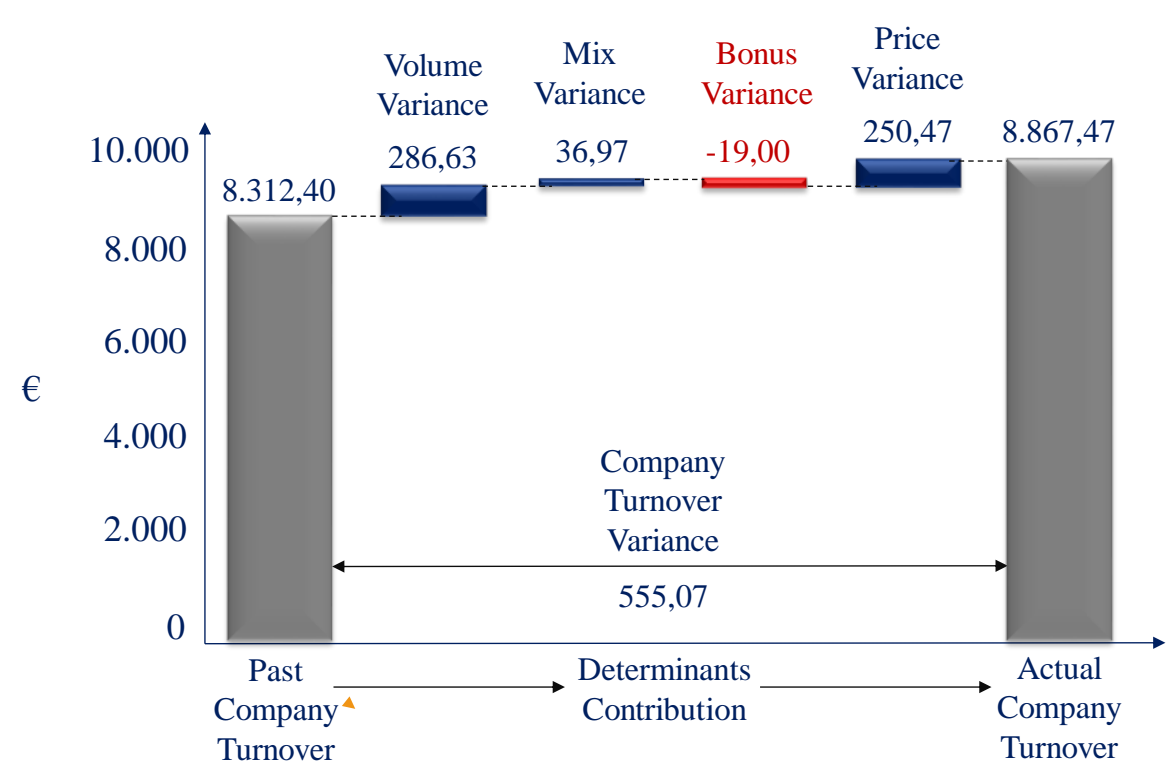

Figure 4. Company turnover variances: the bridge chart

As concerns the compression/expansion chart for the whole company there are always three areas (figure 5):

a. the revenues generated/absorbed by the change in volumes and mix considering the past net prices (bonuses included): it's the so called quantity (volume+mix) effect, $\sum$ (Vc x Mcn - Vc x Mc1) x Pc1 x (1-Bc1)=323,60, it's equal to the sum of the volumes, $+286,63$, and mix variances, 36,97 ;

b. the revenues generated/absorbed by the net price change (bonuses included) in relation to past volumes and mix: it's the so called net price on old quantity (volume+mix) effect, $\quad \sum($ Pc1 x (1-Bc1) - Pc1 x (1-Bc1)) x Vc x $M c 1=265,22$, and it's the first part of the net price variance (price variance $+250,47+$ bonus variance $-19,00=$ 231,47);

c. the change in net prices (bonuses included) related to the change in volumes and mix: this joint area is not usely reported separately but generally is included in the price variance: $\sum(\mathbf{P c 1} \times(1-\mathbf{B c 1})-\mathrm{Pc} 1 \times(1-\mathrm{Bc} 1)-(\mathbf{V c} \times$ Mc1 - Vc x Mc1) $=-33,75$. This amount is the second part of the net price variance (adding 265,22 and $-33,75$ we obtain the net price variance, 231,47). 


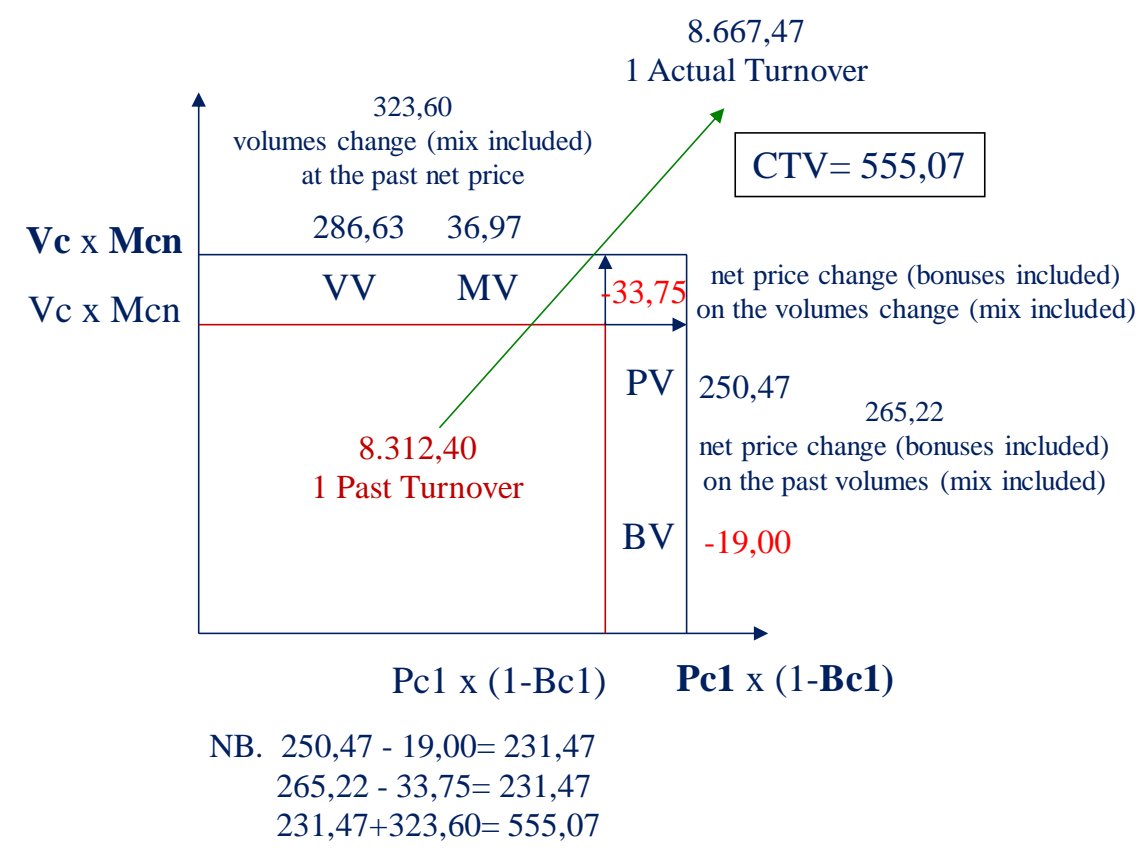

Figure 5. Company turnover variances: the compression expansion chart

From a different point of view, it's interesting to observe that:

a. as a whole, the company's turnover policy is positive, $+555,07$ ( $+6,68 \%$ vs previous year): with a marginal bonus sacrifice, both volumes prices and mix increased;

b. the product 1 replicated the company's performance but the best in class is the product 3: bonuses and prices sacrifices have over boosted mix effect and improved volumes;

c. product 4 recorded a big trade-off between the negative volume/mix effect and the positive price effect: in other words, lower quantities sold at a higher price: more revenues but a smaller presence on the market: a result that needs important reflections;

d. the only negative result concerns the product 2: the price sacrifice did not get a consistent return in terms of volumes/mix.

\subsection{Benchmark Turnover Variances Analysis: From an Internal to a Competitive Analysis}

In the process of managerial awarenesst there is a further information related to the comparison of the company's turnover performance with the market one. We can call it benchmark turnover variances analysis and the objective is to identify for each single turnover determinant the contribution related to the market trend and the differential contribution of the company.

In particular, it is essential to measure, for each single turnover determinant, the difference between the company's performance and those expressed by the whole market. Consequently, the previous four variances analysis begin the following eight:

1. as concern the volumes variance it's possible to identify:

1.1. the market volumes variance, MVV: the turnover change related exclusively to the market trend;

1.2. the company volumes variance, CVV: the turnover change due to the different market share of the company;

2. as regards the mix variance the are two different variances:

2.1. the market mix variance, MMV: the turnover change connected to a difference in the market product mix;

2.2. the company mix variance, $\mathrm{CMV}$ : the turnover change related to the different product mix of the company compared to the market one;

3. the bonus variance includes two variances:

3.1. the market bonus variance, MBV: the turnover change linkable to the modification of the market customer bonus; 
3.2. the company bonus variance $\mathrm{CBV}$ : the turnover change due to the different company customer bonus compared to the market one;

4. the price variance is analysed as follows:

4.1. the market price variance, MPV: the turnover change related to a different market price;

4.2. the company price variance, CPV: the turnover change connected to a different price of the company compared to the market one.

The "benchmark" formula to measure each single turnover determinant both the company and the market is very simple: it is sufficient to multiply and divide each single factor of the previous formula, company turnover variance of table 4 , for the corresponding global market values.

This escamotage has a twofold goal: it allows to identify clearly the contribution of each determinant to the variation of the $n$ company turnover and to distinguish the contribution due to the specific company performance and the one related to the market trend.

In operational terms and with reference to the 1 product:

a. 1 Actual Turnover is equal to the multiplication of six factors based on four determinants: actual company market share $(\mathrm{Vc} / \mathrm{Vm})$, actual global market volumes $(\mathbf{V m})$, actual 1 company/market mix relationship (Mc1/Mm1), actual 1 market mix (Mm1), actual 1 company/market net price relationship ((Pc1 x (1-Bc1)) / $(\mathbf{P m 1} \times(1-\mathbf{B m 1})))$ and actual 1 market net price (Pm1 x (1-Bm1));

b. $\quad 1$ Past Turnover is equal to the multiplication of the same six factors based on the same four determinants: past company market share $(\mathrm{Vc} / \mathrm{Vm})$, past global market volumes $(\mathrm{Vm})$, past 1 company/market mix relationship $(\mathrm{Mc} 1 / \mathrm{Mm} 1)$, past 1 market mix (Mm1), past 1 company/market net price relationship ((Pc1 x (1-Bc1)) / $(\mathrm{Pm} 1 \mathrm{x}$ $(1-\mathrm{Bm} 1)))$ and past 1 market net price $(\mathrm{Pm} 1 \mathrm{x}(1-\mathrm{Bm} 1))$;

c. to obtain the $l$ Company Turnover Variance $1 \mathrm{CVT}$ it is sufficient to properly compose the above actual and past values of the determinants. For the "shifting" and "difference" model, please refer to the above.

1 Benchmark Turnover Variance Analysis through four Determinants compared between Company and Market. The "shifting" model formula:

$$
\begin{aligned}
& 1 \text { Company Turnover Variance CTV } 1 \text { Actual Turnover }-1 \text { Past Turnover= }
\end{aligned}
$$

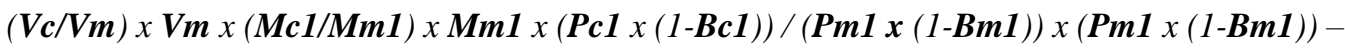

$$
\begin{aligned}
& (\mathrm{Vc} / \mathrm{Vm}) \times \mathrm{Vm} \times(\mathrm{Mcl} / \mathrm{Mml}) \times \mathrm{Mml} \times(\mathrm{Pcl} \times(1-\mathrm{Bcl})) /(\mathrm{Pml} \times(1-\mathrm{Bm} 1)) \times(\mathrm{Pml} \times(1-\mathrm{Bm} 1))= \\
& (900 / 5.910) \times 5.910 \times(17,78 \% / 14,89 \%) \times 14,89 \% \times(9,00 \times(1-3,00 \%)) /(8,75 \times(1-2,25 \%)) \times(8,75 \times(1-2,25 \%))- \\
& (870 / 5.700) \times 5.700 \times(17,24 \% / 15,79 \%) \times 15,79 \% \times(8,00 \times(1-2,50 \%)) /(8,50 \times(1-2,00 \%)) \times(8,50 \times(1-2,00 \%))= \\
& 900 \times \mathbf{1 7 , 7 8 \%} \times \mathbf{8 , 7 3}-870 \times 17,78 \% \times 8,73=1.396,80-1.170,00=+226,80
\end{aligned}
$$

Shift Vm with Vm:

1 Market Volumes Variance MVV=1 Adjusted Actual Market Volumes $-n$ Past Turnover=

$(V c / V m) \times V m \times M c 1 \times P c 1 \times(1-B c 1)-(V c / V m) \times V m \times M c 1 \times P c 1 \times(1-B c 1)=$

$902,05 \times 17,24 \% \times 7,80-870,00 \times 17,24 \% \times 7,80=1.213,11-1.170,00=+43,11$

Shift $\mathrm{Vc} / \mathrm{Vm}$ with $\mathbf{V e} / \mathbf{V m}$ :

1 Company Volumes Variance CVV=1 Adjusted Actual Company Volumes 1 Adjusted Actual Market Volumes=

Vc $\times$ Mc1 $\times$ Pcl $\times(1-B c 1)-(V c / V m) \times$ Vm $\times$ Mc1 $\times$ Pc1 $\times(1-B c 1)=$

$\mathbf{9 0 0 , 0 0} \times 17,24 \% \times 7,80-\mathbf{9 0 2 , 0 5} \times 17,24 \% \times 7,80=1.210,34-1.213,11=-2,76$

Shift Mc1 with Mm1:

1 Market Mix Variance MMV=1 Adjusted Actual Market Mix - 1 Adjusted Actual Company Volumes=

$$
\text { Vc } \times(M c 1 / M m 1) \times \text { Mm1 } \times \text { Pc1 } \times(1-B c 1)-V c \times M c 1 \times P c 1 \times(1-B c 1)=
$$$$
\mathbf{9 0 0 , 0 0} \times \mathbf{1 6 , 2 6 \%} \times 7,80-\mathbf{9 0 0 , 0 0} \times 17,24 \% \times 7,80=1.141,40-1.210,34=-68,95
$$

Shift Mc1/Mm1 with Mc1/Mm1:

1 Company Mix Variance CMV=1 Adjusted Actual Company Mix - 1 Adjusted Actual Market Mix=

$$
\begin{gathered}
V c \times M c 1 \times P c 1 \times(1-B c 1)-V c \times(M c 1 / M m 1) \times \mathbf{M m 1} \times P c 1 \times(1-B c 1)= \\
\mathbf{9 0 0 , 0 0} \times \mathbf{1 7 , 7 8 \%} \times 7,80-\mathbf{9 0 0 , 0 0} \times \mathbf{1 6 , 2 6 \%} \times 7,80= \\
1.248,00-1.141,40=+106,60
\end{gathered}
$$


Shift Bm1 with Bm1 (in the market net price):

1 Market Bonus Variance MBV= 1 Adjusted Actual Market Bonus - 1 Adjusted Actual Company Mix=

Vc $x \operatorname{Mc1} x(P c 1 \times(1-B c 1)) /(P m 1 x(1-B m 1)) x(P m 1 x(1-B m 1))-V c x$ Mc1 $x$ Pcl $x(1-B c 1)=(17)$ $\mathbf{9 0 0 , 0 0} \times \mathbf{1 7 , 7 8 \%} \times \mathbf{7 , 7 8}-\mathbf{9 0 0 , 0 0} \times \mathbf{1 7 , 7 8 \%} \times 7,80=1.244,82-1.248,00=-3,18$

Shift Bc1 with Bc1:

1 Company Bonus Variance CBV=1 Adjusted Actual Company Bonus - 1 Adjusted Actual Market Bonus= Vc $x \operatorname{Mc1} x(P c 1 \times(1-B c 1)) /(P m 1 \times(1-B m 1)) x(P m 1 \times(1-B m 1))-$ Vc $x \operatorname{Mc1} x(P c 1 \times(1-B c 1)) /(P m 1 \times(1-B m 1)) \times(P m 1 \times(1-B m 1))=$ $\mathbf{9 0 0 , 0 0} \times \mathbf{1 7 , 7 8 \%} \times \mathbf{7 , 7 6}-\mathbf{9 0 0 , 0 0} \times \mathbf{1 7 , 7 8 \%} \times \mathbf{7 , 7 8}=1.241,60-1.244,82=-3,22$

Shift Pm1 with Pm1:

1 Market Price Variance MPV= 1 Adjusted Actual Market Price - 1 Adjusted Actual Company Bonus=

Vc $x \operatorname{Mc1} x(P c 1 \times(1-B c 1)) /(P m 1 \times(1-B m 1)) \times(P m 1 \times(1-B m 1))-V c \times M c 1 \times P c 1 \times(1-B c 1)=$ $\mathbf{9 0 0 , 0 0} \times \mathbf{1 7 , 7 8 \%} \times \mathbf{7 , 9 9}-\mathbf{9 0 0 , 0 0} \times \mathbf{1 7 , 7 8 \%} \times \mathbf{7 , 7 6}=1.278,12-1.241,60=+36,52$

Shift Pc1 with Pc1:

1 Company Price Variance CPV=1 Adjusted Actual Company Price - 1 Adjusted Actual Market Price=

1 Adjusted Actual Company Price - 1 Adjusted Actual Market Price =

Vc $x$ Mc1 $x$ Pc1 $x(1-B c 1)-V c x$ Mc1 $x$ Pc1 $x(1-B c 1) /(P m 1 x(1-B m 1)) \times($ Pm1 $x(1-B m 1))=$ $\mathbf{9 0 0 , 0 0} \times \mathbf{1 7 , 7 8 \%} \times \mathbf{8 , 7 3 - 9 0 0 , 0 0} \times \mathbf{1 7 , 7 8 \%} \times \mathbf{7 , 9 9}=1.396,80-1.278,12=+118,68$

Total:

$$
\begin{gathered}
1 \text { Company Turnover Variance } C T V=\sum 8 \text { single variances }= \\
M V V+C V V+M M V+C M V+M B V+C B V+M P V+C P V= \\
43,11-2,76-68,95+106,60-3,18-3,22+36,52+118,68=+226,80
\end{gathered}
$$

1 Benchmark Turnover Variance Analysis through four Determinants compared between Company and Market. The "difference" model formula:

1 Company Turnover Variance CTV= 1 Actual Turnover -1 Past Turnover=

$(\mathrm{Vc} / \mathrm{Vm}) \times \mathrm{Vm} \times(\mathrm{Mc1/Mm1}) \times \mathrm{Mm1} x(\mathrm{Pc1} x(1-\mathrm{Bc1})) /(\mathrm{Pm} 1 \times(1-\mathrm{Bm} 1)) x(\mathrm{Pm} 1 \times(1-\mathrm{Bm} 1))-$

$(\mathrm{Vc} / \mathrm{Vm}) \times \mathrm{Vm} \times(\mathrm{Mcl} / \mathrm{Mml}) \times \mathrm{Mml} \times(\mathrm{Pcl} \times(1-\mathrm{Bcl})) /(\mathrm{Pml} \times(1-\mathrm{Bml})) \times(\mathrm{Pml} \times(1-\mathrm{Bml}))=(\mathbf{9 0 0 / 5 . 9 1 0}) \times \mathbf{5 . 9 1 0} \times$

$(17,78 \% / 14,89 \%) \times 14,89 \% \times(9,00 \times(1-3,00 \%)) /$

$(8,75 \times(1-2,25 \%)) \times(8,75 \times(1-2,25 \%))-(870 / 5.700) \times 5.700 x$

$(17,24 \% / 15,79 \%) \times 15,79 \% \times(8,00 \times(1-2,50 \%)) /(8,50 \times(1-2,00 \%)) \times(8,50 \times(1-2,00 \%))=$

$900 \times \mathbf{1 7 , 7 8 \%} \times 8,73-870 \times 17,78 \% \times 8,73=1.396,80-1.170,00=226,80$

Volumes Difference Vc $-\mathbf{V m}=\mathbf{5 . 9 1 0 , 0 0}-5.700,00$ :

1 Market Volumes Variance MVV= 1 Adjusted Actual Market Volumes $-n$ Past Turnover=

$(\mathrm{Vc} / \mathrm{Vm}) \times(\mathbf{V m}-\mathrm{Vm}) \times \mathrm{Mcl} \times \mathrm{Pcl} \times(1-\mathrm{Bcl})=15,26 \% \times(\mathbf{5 . 9 1 0 , 0 0}-5.700,00) \times 17,24 \% \times 7,80=43,11$

Market Share Difference MS - MS= 15,23\%-15,26\%:

1 Company Volumes Variance CVV= 1 Adjusted Actual Company Volumes - 1 Adjusted Actual Market

Volumes $=$ Vm $x($ MS $-M S) \times M c 1 \times P c 1 \times(1-B c 1)=$

$$
\mathbf{5 . 9 1 0 , 0 0} \times(15,26 \%-\mathbf{1 5 , 2 3 \%}) \times 17,24 \% \times 7,80=-2,76
$$

Market Mix Difference Mm1 - Mm1= 14,89\% - 15,79\%:

1 Market Mix Variance MMV= 1 Adjusted Actual Market Mix - 1 Adjusted Actual Company Volumes=

Vm $x$ MS $x$ Mcl/Mml $x(\mathbf{M m 1}-\mathrm{Mml}) \times$ Pcl $x(1-B c 1)=$

$$
\mathbf{5 . 9 1 0 , 0 0} \times \mathbf{1 5 , 2 3 \%} \times 17,24 \% / 15,79 \% \times(\mathbf{1 4 , 8 9 \%}-15,79 \%) \times 7,80=-68,95
$$


Company/Market Mix Relationship Difference (RcmM1-RcmM1)= 17,78\%/14,89\% - 17,24\%/15,79\%:

1 Company Mix Variance CMV=1 Adjusted Actual Company Mix - 1 Adjusted Actual Market Mix=

Vm $x$ MS $x$ Mm1 $x$ (RcmM1-RcmM1) $x$ Pcl $x(1-B c 1)=$

$\mathbf{5 . 9 1 0 , 0 0} \times \mathbf{1 5 , 2 3 \%} \times \mathbf{1 4 , 8 9 \%} \times(\mathbf{1 7 , 7 8 \%} / \mathbf{1 4 , 8 9 \%}-17,24 \% / 15,79 \%) \times 7,80=+106,60$

Market Bonus Difference ((1-Bm1 ) / (1-Bm1)-1) $=((1-2,25 \%) /(1-2,00 \%)-1)$ :

1 Market Bonus Variance MBV=1 Adjusted Actual Market Bonus - 1 Adjusted Actual Company Mix=

Vm $x$ MS $x$ Mc1 $x$ RcmM1 $x$ Pcl $x$ (1-Bc1) $x((1-B m 1) /(1-B m 1)-1)=$

$\mathbf{5 . 9 1 0 , 0 0} \times \mathbf{1 5 , 2 3 \%} \times \mathbf{1 4 , 8 9 \%} \times \mathbf{1 7 , 2 4 \%} / \mathbf{1 5 , 7 9 \%} \times 7,80 \times((1-2,25 \%) /(1-2,00 \%)-1)=-3,18$

Company Bonus Difference Pc1 x (1-Bc1) - $(\mathrm{Pc} 1 \mathrm{x}(1-\mathrm{Bc} 1) \times(1-\mathrm{Bm} 1) /(1-\mathrm{Bm} 1))=7,76-7,80 \mathrm{x}$ $(1-2,25 \%) /(1-2,00 \%)$ :

1 Company Bonus Variance CBV=1 Adjusted Actual Company Bonus -1 Adjusted Actual Market Bonus=

Vm $x$ MS $x$ Mc1 $x$ RcmM1 $x$ [(Pc1 $x(1-B c 1))-(P c 1 \times(1-B c 1)) \times(1-B m 1) /(1-B m 1)]=$

$$
\mathbf{5 , 9 1 0 , 0 0} \times \mathbf{1 5 , 2 3 \%} \times \mathbf{1 4 , 8 9 \%} \times \mathbf{1 7 , 2 4 \%} / \mathbf{1 5 , 7 9 \%} \times(\mathbf{7 , 7 6}-7,80) \times(1-2,25 \%) /(1-2,00 \%)=-3,22
$$

Market Price Difference (Pm1/Pm1)-1= (8,75/8,50)-1:

1 Market Price Variance MPV=1 Adjusted Actual Market Price -1 Adjusted Actual Company Bonus=

Vm $x$ MS $x$ Mc1 $x$ RcmM1 $x($ Pc1 $x$ (1-Bc1) $x(($ Pm1/Pm1 $)-1)=$

$$
5.910,00 \times 15,23 \% \times 18,49 \% \times 17,24 \% / 15,79 \% \times-7,76 \times((8,75 / 8,50)-1)=+36,52
$$

Company Price Difference $(\mathbf{P c 1}-\mathrm{Pc} 1$ x Pm1/Pm1) $=(\mathbf{9 , 0 0}-8,00$ x 8,75/8,50)

1 Company Price Variance CPV=1 Adjusted Actual Company Price -1 Adjusted Actual Market Price=

Vm $x$ MS $x$ Mc1 $x(1-B c 1) \times(P c 1-P c n \times$ Pm1/Pm1 $)=$

$$
\mathbf{5 . 9 1 0 , 0 0} \times \mathbf{1 5 , 2 3 \%} \times \mathbf{1 8 , 4 9 \%} \times(1-3,00 \%) \times(\mathbf{9 , 0 0 - 8 , 0 0} \times \mathbf{8 , 7 5} / 8,50)=+118,68
$$

Total:

$$
\begin{gathered}
1 \text { Company Turnover Variance } C T V=\sum 8 \text { single variances }= \\
M V V+C V V+M M V+C M V+M B V+C B V+M P V+C P V= \\
43,11-2,76-68,95+106,60-3,18-3,22+36,52+118,68=226,80
\end{gathered}
$$

To obtain the company turnover variance, CTV, distinguishing the specific contributions of the market and the company, it is sufficient to add up all the company turnover variances (table 5). It' very interesting to highlight ${ }^{4}$ :

a. the market push contributed for 199,08 to the positive company turnover variance of 555,07 and then the company outperformed for 355,99: in other word if the company had performed like the market trend, its turnover would have grown by 199,08: but as the company's turnover has increased by 555,07, this means that the company has achieved an outperformance of turnover of 355,99 ;

b. the company outperformance for $+355,99$ (vs market trend of $+199,08$ ) is particularly focused on the product 4 $(+439,76$ vs $-290,24)$ : this means that if the company had followed the market trend the contribution to the turnover would have been equal to $+199,08$ (and $-290,24$ for the product 4 ) but the company outperformed for further $+355,99(+439,76$ for the product 4$)$ : the company turnover variance in fact was equal to $+555,07$ $(+149,52$ for the product 4$)$ that is the sum of the performance pushed by the market and the further positive performance of the company;

c. the market trend was positive, in terms of push to the company turnover, above all in relation to the determinant of volumes, $+306,25$, and secondly to the determinant of prices, $+49,67$. As concerns prices company outperformed the market, positive for 49,67, for 200,80: this means that if the company had followed the market trend the contribution to the turnover would have been equal to $+49,67$ but the company outperformed for further $+200,80$;

d. as regards the determinants, the biggest difference between the market and the company performance it was highlighted in the volumes where the company was unable to keep up the rhythm of the market: $+306,25$ for the latter and $-19,61$ for the company. The company volumes variance is equal to $+286,63$; on the contrary the 
company outperformed as concerns mix $(+129,83$ vs $-92,86)$, bonuses $(+44,98$ vs $-63,98)$ and prices $(+200,80$ vs +49,67);

e. in short, the company has not fully exploited the market's push on volumes (it could have increased its turnover by 306,25 instead of 286,63), but it was more able than the market to sell products with higher unit price (if it had followed the market trend it would have realized a lower turnover for $-92,86$ and instead of increasing it by $+36,97$ with an outperformance of $+129,83$ ) granting smaller bonuses (with an outperformance of $+44,98$ compared to the market trend of $-63,98)$ and selling at a higher price $(+200,80$ of outperformance compared to the market trend of $+49,67)$.

Table 5. Benchmark turnover variances as sum of volumes, mix, bonuses and prices company turnover variances driven by market and company (in brackets the percentage change related to the past company turnover of $8.312,40$ )

\begin{tabular}{|c|c|c|c|c|c|c|c|}
\hline \multicolumn{2}{|c|}{ Company Turnover Variances } & \multirow{2}{*}{$\begin{array}{c}\text { Product } 1 \\
43,11 \\
(0,52 \%)\end{array}$} & \multirow{2}{*}{$\begin{array}{c}\text { Product } 2 \\
69,26 \\
(0,83 \%)\end{array}$} & \multirow{2}{*}{$\begin{array}{c}\text { Product } 3 \\
50,93 \\
(0,61 \%)\end{array}$} & \multirow{2}{*}{$\begin{array}{c}\text { Product } 4 \\
142,95 \\
(1,72 \%)\end{array}$} & \multicolumn{2}{|c|}{ Total } \\
\hline Company Volume & By Market & & & & & $\begin{array}{c}306,25 \\
(+3,68 \%)\end{array}$ & $+286,63$ \\
\hline Variance & By Company & $\begin{array}{c}-2,76 \\
(-0,03 \%)\end{array}$ & $\begin{array}{c}-4,44 \\
(-0,05 \%)\end{array}$ & $\begin{array}{c}-3,26 \\
(-0,04 \%)\end{array}$ & $\begin{array}{c}-9,15 \\
(-0,11 \%)\end{array}$ & $\begin{array}{c}-19,61 \\
(-0,24 \%)\end{array}$ & $(+3,45 \%)$ \\
\hline Company Mix & By Market & $\begin{array}{c}-68,95 \\
(-0,83 \%)\end{array}$ & $\begin{array}{c}68,45 \\
(0,82 \%)\end{array}$ & $\begin{array}{c}108,33 \\
(+1,30 \%)\end{array}$ & $\begin{array}{l}-200,69 \\
(-2,41 \%)\end{array}$ & $\begin{array}{c}-92,86 \\
(-1,12 \%)\end{array}$ & $+36,97$ \\
\hline Variance & By Company & $\begin{array}{c}106,60 \\
(1,28 \%)\end{array}$ & $\begin{array}{c}-39,27 \\
(-0,47 \%)\end{array}$ & $\begin{array}{c}189,60 \\
(2,28 \%)\end{array}$ & $\begin{array}{l}-127,10 \\
(-1,53 \%)\end{array}$ & $\begin{array}{c}129,83 \\
(1,56 \%)\end{array}$ & $(+0,44 \%)$ \\
\hline Company Bonus & By Market & $\begin{array}{c}-3,18 \\
(-0,04 \%)\end{array}$ & $\begin{array}{c}5,19 \\
(0,06 \%)\end{array}$ & $\begin{array}{c}0,00 \\
(0,00 \%)\end{array}$ & $\begin{array}{c}-65,99 \\
(0,79 \%)\end{array}$ & $\begin{array}{c}-63,98 \\
(-0,77 \%)\end{array}$ & $-19,00$ \\
\hline Variance & By Company & $\begin{array}{c}-3,22 \\
(-0,04)\end{array}$ & $\begin{array}{l}15,81 \\
(0,19)\end{array}$ & $\begin{array}{l}-10,80 \\
(-0,13)\end{array}$ & $\begin{array}{l}43,19 \\
(0,52)\end{array}$ & $\begin{array}{l}44,98 \\
(0,54)\end{array}$ & $(-0,23 \%)$ \\
\hline Company Price & By Market & $\begin{array}{c}36,52 \\
(0,44 \%)\end{array}$ & $\begin{array}{c}105,00 \\
(1,26 \%)\end{array}$ & $\begin{array}{c}74,66 \\
(0,90 \%)\end{array}$ & $\begin{array}{l}-166,51 \\
(-2,00 \%)\end{array}$ & $\begin{array}{c}49,67 \\
(+0,60 \%)\end{array}$ & $+250,47$ \\
\hline Variance & By Company & $\begin{array}{c}118,68 \\
(1,43 \%)\end{array}$ & $\begin{array}{l}-304,50 \\
(-3,66 \%)\end{array}$ & $\begin{array}{l}-146,21 \\
(-1,76 \%)\end{array}$ & $\begin{array}{c}532,83 \\
(6,41 \%)\end{array}$ & $\begin{array}{c}200,80 \\
(2,42 \%)\end{array}$ & $(+3,01 \%)$ \\
\hline Company Turnover & By Market & $\begin{array}{c}7,49 \\
(0,09 \%)\end{array}$ & $\begin{array}{c}247,91 \\
(2,98 \%)\end{array}$ & $\begin{array}{c}233,92 \\
(2,81 \%)\end{array}$ & $\begin{array}{l}-290,24 \\
(-3,49 \%)\end{array}$ & $\begin{array}{c}199,08 \\
(2,39 \%)\end{array}$ & $+555,07$ \\
\hline Variance & By Company & $\begin{array}{c}219,31 \\
(2,64 \%)\end{array}$ & $\begin{array}{l}-332,41 \\
(-4,00 \%)\end{array}$ & $\begin{array}{c}29,33 \\
(0,35 \%)\end{array}$ & $\begin{array}{c}439,76 \\
(5,29 \%)\end{array}$ & $\begin{array}{c}355,99 \\
(4,28 \%)\end{array}$ & $(+6,68 \%)$ \\
\hline $\begin{array}{c}\text { Company Turnover } \\
\text { Variance }\end{array}$ & & $\begin{array}{c}226,80 \\
(2,73 \%)\end{array}$ & $\begin{array}{c}-84,50 \\
(1,02 \%)\end{array}$ & $\begin{array}{c}263,25 \\
(3,17 \%)\end{array}$ & $\begin{array}{c}149,52 \\
(1,80 \%)\end{array}$ & $\begin{array}{c}555,07 \\
(+6,68 \%)\end{array}$ & \\
\hline
\end{tabular}

Also for the benchmark turnover variance analysis the bridge graph makes immediately visible the contribution of each determinant to the passage between past and current company turnover (figure 10):

a. if the company had aligned itself with the volumes market trend, turnover would have increased by $+306,25$ to reach $8.618,65$; but the company underperformed for $-19,61$ and therefore the turnover increased for the volumes variance up to $8.599,03$, other things being equal: the difference between the actual turnover, $8.867,47$, and 8.599,03 is related to the mix, bonuses and prices determinants;

b. the mix market trend would have reduced the company's turnover by $-92,86$, but the outperformance of the latter, $+129,83$, would have led to a turnover equal to $8.636,00$, bonuses and prices being equal;

c. market bonus variance was negative for $-63,98$ in terms of company turnover but also in this case the company outperformed for $+44,98$ because the lower bonuses granted to customers, and the current turnover should have been equal to $8.617,00$. The difference $8.867,47-8.617,00$, equal to 250,47 , is related to greater actual prices both the market but overall thanks to the company outperformance for 200,80 . 


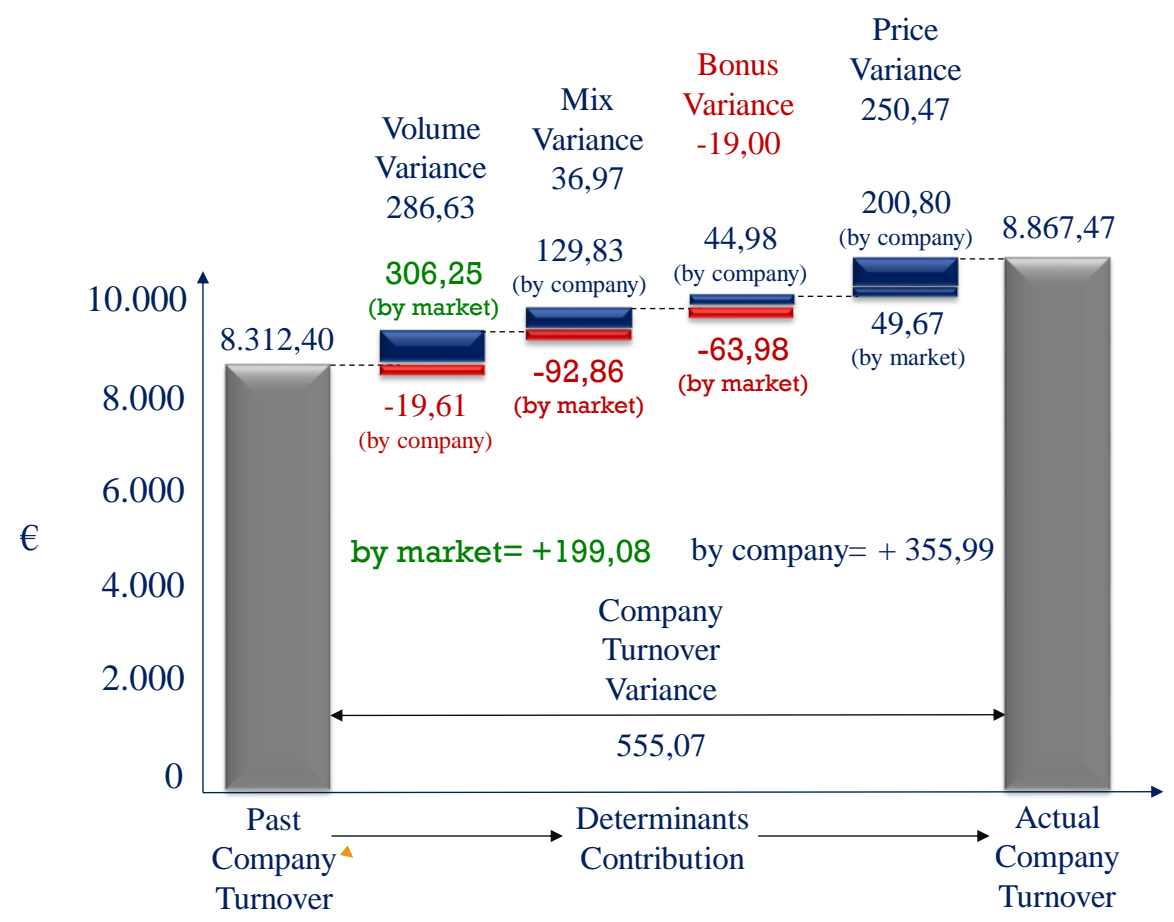

Figure 10. Company turnover variances by market trend and by company performance: the bridge chart

From a different point of view, it's interesting to observe that:

a. as a whole, the company's turnover policy has been positive, $+555,07(+6,68 \%$ vs previous year) and better than the market one, $+6,68 \%$ vs $+2,39 \%$ : a lower bonus sacrifice for the company $(-0,23 \%$ vs $-0,77 \%)$, a better performance in mix $(+0,44 \%$ vs $-1,12 \%)$ and prices $(+3,01 \%$ vs $+0,60 \%)$ and a lower performance in volumes $(+3,45 \%$ vs $+3,68 \%)$;

b. as concerns the product $l$ company has overperformed the market, $+2,64 \%$ vs $+0,09 \%$, thanks to mix and prices effects;

c. as regards the product 3 company underpeformed the market, $+0,35 \%$ vs $+3,17 \%$, because of prices, bonuses and volumes;

d. product 4 has recorded the best additional performance for the company, $+5,29 \%$ vs $-3,49 \%$, thanks to prices and bonuses with a marginal sacrifice in volumes;

e. the only negative result concerns the product 2: company has underperformed the market, $-4,00 \%$ vs $+2,98 \%$, especially due to prices and mix/volumes.

In the specific numerical example, the company succeeded, above all thanks to the market push, to improve sales volumes, with an effect on sales of $3,45 \%$, increasing at the same time, and more than the market, the prices, with a positive effect on the turnover equal to $+3,01 \%$ : in summary the company has used the market push to increase the prices obtaining with this choice an increase of turnover equal to $+6,46 \%$.

But the company also achieved two further positive results: it raised the level of the range of volumes sold, with an effect on sales of $+1,56 \%$, partly reduced by the opposite effect of the market of $-1,12 \%$, and it sold the highest range level range at a higher price, with an increase in turnover of $+2,96 \%$, reduced by $-0,17 \%$ by the opposite effect of the market.

\section{Turnover Variances Analysis and the Independent After Market arena}

The case study chosen for the application of the turnover variances analysis is related to the Automotive Independent After Market, IAM, sector (Guelfi S. 2013).

The Automotive IAM sector is the "equivalent" alternative of the original automotive spare parts (OE) supplied by the official dealers. In 2017 Italy has the highest number of IAM operators in Europe: 160 Spare Parts Distributors, 
4.400 Spare Parts Shops and over 50.000 Car Repair Garages (IAM+OE) for a car fleet of 38.500.000 (over 3.800 Official Car Dealers, 20.000 Car Body Repair Garages, 1.700 Car Compactors and many other automotive operators) (figure 11). IAM sector is anticyclical and the economic crisis worked as a catalyst for the development of revenues with an IAM market share gown up to $68 \%$ (Guelfi S., et al. 2016).

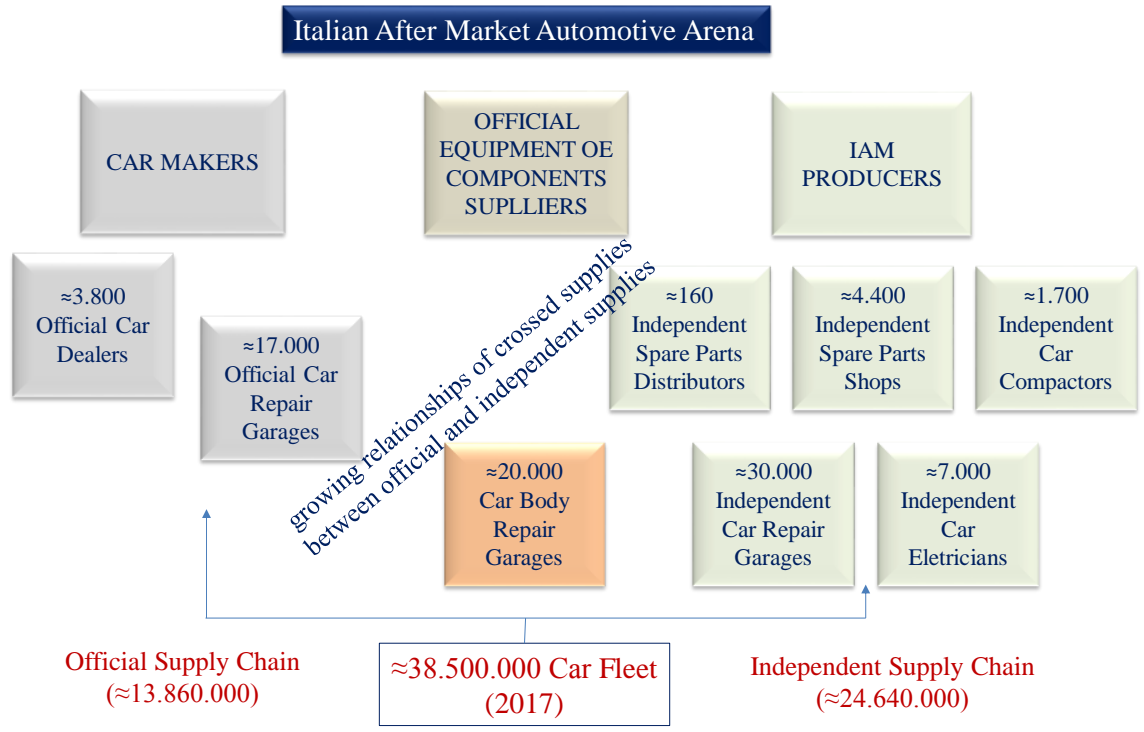

Figure 11. The Italian after market automotive arena (2017, excluding tire shops, glass centers)

The data used for the turnover variances analysis are collected and provided by the IAM Observatory of the Polytechnic University of Turin and the analysis is focused on the first twelve Product Categories sold by the Distributors in 2017 (turnover and volumes are expressed in thousands). The IAM Observatory collects and analyses, every month from 2012, the 51,86\% of the Italian IAM Distributors sell-out (in the 2017 this market, excluding tires, car body, car glasses and lubricants oil, is worth around 1,85 billion of euro which becomes 3,40 billion of euro at the next level of the Spare Parts Shops). This sell-out it's measured in terms of volumes, product mix, prices, customer bonus, purchasing costs, etc. for 220 Product Categories and over 600 Brands. As the data of the specific companies are protected by confidentiality, for the paper has been created a Mr. Distributor (as a company "c") as the sum of two main companies of the sample such that the sum of their market shares does not exceed $20 \%$.

As concerns the numerical results, the following tables 6, 7,8 and 9 show the values of the turnover determinants respectively:

- $\quad$ for the company and for the related global market (excluding the company);

- $\quad$ for the twelve best seller category products for the Mr. Distributor;

- $\quad$ for the past (year 2016) and actual (year 2017) performance;

- the mix variance refers to the twelve product categories analyzed.

Table 6. Company turnover determinants: past product performance (year 2016)

\begin{tabular}{|c|c|c|c|c|c|c|c|c|c|c|c|c|c|c|}
\hline Sequence & $\begin{array}{l}\text { Past Company Values } \\
\text { (2016) }\end{array}$ & $\mathrm{BP}$ & CK & $\mathrm{CB}$ & DK & $\mathrm{BD}$ & $\mathrm{FF}$ & FW & SS & SA & AS & $\mathrm{AF}$ & WP & Total \\
\hline A & Volumes (Vc) & 520 & 113 & 163 & 186 & 201 & 436 & 20 & 317 & 117 & 32 & 618 & 180 & 2.903 \\
\hline $\mathrm{C}$ & Unit Price $(\mathrm{Pc})$ & 21,86 & 82,58 & 44,39 & 40,03 & 23,68 & 10,84 & 243,51 & 15,65 & 35,11 & 128,54 & 6,56 & 23,58 & \\
\hline $\mathrm{D}$ & Mix (Mc) & $17,90 \%$ & $3,88 \%$ & $5,63 \%$ & $6,42 \%$ & $6,92 \%$ & $15,01 \%$ & $0,69 \%$ & $10,91 \%$ & $4,02 \%$ & $1,12 \%$ & $21,28 \%$ & $6,21 \%$ & $100,00 \%$ \\
\hline \multicolumn{15}{|l|}{$\mathrm{E}=\mathrm{A} \cdot \mathrm{C} \bullet$} \\
\hline$(1-B)$ & Turnover $(\mathrm{Tc})$ & 11.365 & 9.297 & 7.255 & 7.461 & 4.757 & 4.726 & 4.854 & 4.959 & 4.102 & 4.173 & 4.054 & 4.251 & 71.253 \\
\hline
\end{tabular}

Table 7. Global market turnover determinants: past product performance (year 2016) 


\begin{tabular}{|c|c|c|c|c|c|c|c|c|c|c|c|c|c|c|}
\hline Sequence & $\begin{array}{l}\text { Past Global Market Values } \\
\text { (2016) }\end{array}$ & $\mathrm{BP}$ & CK & $\mathrm{CB}$ & DK & $\mathrm{BD}$ & FF & FW & SS & SA & AS & $\mathrm{AF}$ & WP & Total \\
\hline 1 & Volumes (Vm) & 2.700 & 524 & 1.152 & 618 & 967 & 2.459 & 81 & 1.738 & 921 & 187 & 3.086 & 582 & 15.014 \\
\hline 2 & Bonus Percentage (Bm) & $2,50 \%$ & $2,50 \%$ & $2,50 \%$ & $2,50 \%$ & $2,50 \%$ & $2,50 \%$ & $2,50 \%$ & $2,50 \%$ & $2,50 \%$ & $2,50 \%$ & $2,50 \%$ & $2,50 \%$ & \\
\hline 3 & Unit Price (Pm) & 18,65 & 78,40 & 39,27 & 38,68 & 20,49 & 8,74 & 237,97 & 15,16 & 31,17 & 93,01 & 6,18 & 22,71 & \\
\hline 4 & $\operatorname{Mix}(\mathrm{Mm})$ & $17,98 \%$ & $3,49 \%$ & $7,67 \%$ & $4,12 \%$ & $6,44 \%$ & $16,38 \%$ & $0,54 \%$ & $11,58 \%$ & $6,13 \%$ & $1,24 \%$ & $20,55 \%$ & $3,88 \%$ & $100,00 \%$ \\
\hline \multicolumn{15}{|l|}{$\mathrm{E}=\mathrm{A} \cdot \mathrm{C} \cdot$} \\
\hline$(1-B)$ & Turnover $(\mathrm{Tm})$ & 50.361 & 41.062 & 45.231 & 23.915 & 19.827 & 21.482 & 19.179 & 26.339 & 28.709 & 17.372 & 19.072 & 13.229 & 325.778 \\
\hline
\end{tabular}

Table 8. Company turnover determinants: actual product performance (year 2017)

\begin{tabular}{|c|c|c|c|c|c|c|c|c|c|c|c|c|c|c|}
\hline Sequence & $\begin{array}{l}\text { Actual Company Values } \\
\text { (2017) }\end{array}$ & BP & CK & $\mathrm{CB}$ & DK & $\mathrm{BD}$ & $\mathrm{FF}$ & FW & SS & SA & AS & $\mathrm{AF}$ & WP & Total \\
\hline 1 & Volumes (Vc) & 565 & 115 & 181 & 193 & 224 & 452 & 19 & 301 & 126 & 34 & 640 & 174 & 3.023 \\
\hline 2 & Bonus Percentage $(\mathrm{Bc})$ & $4,00 \%$ & $4,00 \%$ & $4,00 \%$ & $4,00 \%$ & $4,00 \%$ & $4,00 \%$ & $4,00 \%$ & $4,00 \%$ & $4,00 \%$ & $4,00 \%$ & $4,00 \%$ & $4,00 \%$ & \\
\hline 3 & Unit Price $(\mathrm{Pc})$ & 21,08 & 82,52 & 46,92 & 38,27 & 22,76 & 10,74 & 249,17 & 15,50 & 33,55 & 125,32 & 6,57 & 23,43 & \\
\hline 4 & $\operatorname{Mix}(\mathrm{Mc})$ & $18,67 \%$ & $3,79 \%$ & $6,00 \%$ & $6,39 \%$ & $7,42 \%$ & $14,95 \%$ & $0,64 \%$ & $9,96 \%$ & $4,17 \%$ & $1,12 \%$ & $21,17 \%$ & $5,74 \%$ & $100,00 \%$ \\
\hline \multicolumn{15}{|l|}{$\mathrm{E}=\mathrm{A} \cdot \mathrm{C} \bullet$} \\
\hline$(1-B)$ & Turnover (Tc) & 11.901 & 9.449 & 8.504 & 7.389 & 5.104 & 4.854 & 4.812 & 4.664 & 4.231 & 4.230 & 4.201 & 4.068 & 73.409 \\
\hline
\end{tabular}

Table 9. Global market turnover determinants: actual product performance (year 2017)

\begin{tabular}{|c|c|c|c|c|c|c|c|c|c|c|c|c|c|c|}
\hline Sequence & $\begin{array}{l}\text { Actual Global Market Values } \\
\text { (2017) }\end{array}$ & $\mathrm{BP}$ & CK & $\mathrm{CB}$ & DK & $\mathrm{BD}$ & FF & FW & SS & SA & AS & $\mathrm{AF}$ & WP & Total \\
\hline 1 & Volumes (Vm) & 2.572 & 551 & 1.181 & 592 & 986 & 2.405 & 88 & 1.674 & 913 & 199 & 3.064 & 553 & 14.778 \\
\hline 2 & Bonus Percentage $(\mathrm{Bm})$ & $3,50 \%$ & $3,50 \%$ & $3,50 \%$ & $3,50 \%$ & $3,50 \%$ & $3,50 \%$ & $3,50 \%$ & $3,50 \%$ & $3,50 \%$ & $3,50 \%$ & $3,50 \%$ & $3,50 \%$ & \\
\hline 3 & Unit Price $(\mathrm{Pm})$ & 18,82 & 79,00 & 41,29 & 39,58 & 20,74 & 8,93 & 245,58 & 15,51 & 30,45 & 89,52 & 6,09 & 22,88 & \\
\hline 4 & $\operatorname{Mix}(\mathrm{Mm})$ & $17,40 \%$ & $3,73 \%$ & $7,99 \%$ & $4,01 \%$ & $6,67 \%$ & $16,27 \%$ & $0,60 \%$ & $11,33 \%$ & $6,18 \%$ & $1,35 \%$ & $20,74 \%$ & $3,74 \%$ & $100,00 \%$ \\
\hline \multicolumn{15}{|l|}{$\mathrm{E}=\mathrm{A} \cdot \mathrm{C} \bullet$} \\
\hline$(1-B)$ & Turnover (Tm) & 48.406 & 43.559 & 48.750 & 23.434 & 20.442 & 21.474 & 21.652 & 25.961 & 27.806 & 17.859 & 18.671 & 12.652 & 330.667 \\
\hline
\end{tabular}

$\mathrm{BP}=$ Brake Pads, $\mathrm{CK}=$ Cluck Kit, $\mathrm{CB}=$ Car Batteries, $\mathrm{DK}=$ Distribution Kit, $\mathrm{BD}=$ Brake Discs, FF $=$ Fuel Filters, FW $=$ Flywheels, SS $=$ Steering and Suspension, $\mathrm{SA}=$ Shock Absorbers, AS = Alternators and Starters, AF = Air Filters and WP $=$ Water Pumps

In the numerical case, the attention is focused on measuring the performance of the company and the market. The scope is to distinguish for each individual determinant of the turnover the contribution corresponding to the market trend and the differential contribution of the company.

To obtain the company turnover variance, CTV, distinguishing the market and the company contribution, it is sufficient to add up all the company turnover variances (table 10). It' very interesting to highlight:

a. the market push contributed for +286 to the positive company turnover variance of +1.179 and then the company outperformed for +893 : in other words if the company has performed like the market trend, its turnover would have increased by +286 : but as the company's turnover has increased by +1.179 with an outperformance of +893 ;

b. the company outperformance for +893 (vs market trend of +286 ) is concentrated in eight product categories. In the other four product categories the market performs better;

c. Brake Pads BP are the product category with the higher difference between the performance of the company and the market performance, +934 vs -560 : this means that if the company has followed the market trend the contribution to the turnover would have been equal to +286 (-560 for the BP) but the company outperformed for further +893 ( +934 for the $\mathrm{BP})$ : the company turnover variance in fact was equal to $+1.179(+373$ for the $\mathrm{BP})$ that is the sum of the performance pushed by the market and the further positive performance of the company;

d. the market trend was positive, in terms of push to the company turnover (exactly +286$)$, in relation to the determinant of mix (+1.237 vs -1.183$)$ and price (+880 vs -1.697$)$. This means that if the company has followed the market trend the contribution to the turnover would have been equal to $+2.117(+1.237+880)$; 
e. as regards the determinants, the biggest difference between the market and the company performance it was highlighted in the volumes where the market is unable to keep up the rhythm of the company: +3.961 for the latter and -1.090 for the market. The company volume variance is equal to +2.871 ;

f. in short, the company outperformed vs market only in terms of volumes (if it has followed the market trend it would have realized a lower turnover for -1.090 instead of increasing it by +2.871 with an outperformance of +3.961 ). The market is able to sell product with higher quality in terms of mix (if it has followed the company trend it would have realized a lower turnover for -1.183 instead of increasing it by +54 with an outperformance of +1.237$)$ and with an higher price (+880 of outperformance compared to the company trend of -1.697$)$. Regarding bonus, the market and the company have reduced the turnover, but the market performed better than the company -741 vs -928 (in other words company realised, compared to the market, an additional negative performance of -188).

Table 10. Benchmark turnover variance as sum of volumes, mix, bonuses and prices company turnover variances driven by market and company (in italic the percentage change related to the past company turnover of 69.294)

\begin{tabular}{|c|c|c|c|c|c|c|c|c|c|c|c|c|c|c|c|}
\hline $\begin{array}{r}\text { Company } \\
\text { Varia }\end{array}$ & $\begin{array}{l}\text { urnover } \\
\text { ces }\end{array}$ & $\mathrm{BP}$ & CK & $\mathrm{CB}$ & DK & $\mathrm{BD}$ & $\mathrm{FF}$ & FW & SS & SA & AS & $\mathrm{AF}$ & WP & \multicolumn{2}{|c|}{ Total } \\
\hline \multirow{3}{*}{$\begin{array}{l}\text { Company } \\
\text { Volumes }\end{array}$} & \multirow{2}{*}{ By Market } & -174 & -142 & -111 & -114 & -73 & -72 & -74 & -76 & -63 & -64 & -62 & -65 & -1.090 & \\
\hline & & $-0,25 \%$ & $-0,21 \%$ & $-0,16 \%$ & $-0,16 \%$ & $-0,11 \%$ & $-0,10 \%$ & $-0,11 \%$ & $-0,11 \%$ & $-0,09 \%$ & $-0,09 \%$ & $-0,09 \%$ & $-0,09 \%$ & $-1,57 \%$ & 2.871 \\
\hline & By & 632 & 517 & 403 & 415 & 264 & 263 & 270 & 276 & 228 & 232 & 225 & 236 & 3.961 & $4,15 \%$ \\
\hline Variance & Company & $0,91 \%$ & $0,75 \%$ & $0,58 \%$ & $0,60 \%$ & $0,38 \%$ & $0,38 \%$ & $0,39 \%$ & $0,40 \%$ & $0,33 \%$ & $0,33 \%$ & $0,33 \%$ & $0,34 \%$ & $5,72 \%$ & \\
\hline \multirow[b]{2}{*}{ Company Mix } & \multirow{2}{*}{ By Market } & -371 & 655 & 303 & -204 & 169 & -30 & 548 & -108 & 31 & 360 & 37 & -153 & 1.237 & \\
\hline & & $-0,54 \%$ & $0,95 \%$ & $0,44 \%$ & $-0,29 \%$ & $0,24 \%$ & $-0,04 \%$ & $0,79 \%$ & $-0,16 \%$ & $0,04 \%$ & $0,52 \%$ & $0,05 \%$ & $-0,22 \%$ & $1,78 \%$ & 54 \\
\hline \multirow[t]{2}{*}{ Variance } & By & 865 & -874 & 173 & 165 & 178 & 9 & -890 & -333 & 120 & -367 & -59 & -171 & -1.183 & $0,07 \%$ \\
\hline & Company & $1,25 \%$ & $-1,26 \%$ & $0,25 \%$ & $0,24 \%$ & $0,26 \%$ & $0,01 \%$ & $-1,28 \%$ & $-0,48 \%$ & $0,17 \%$ & $-0,53 \%$ & $-0,08 \%$ & $-0,25 \%$ & $-1,71 \%$ & \\
\hline & \multirow{2}{*}{ By Market } & -123 & -94 & -80 & -77 & -53 & -49 & -47 & -47 & -44 & -43 & -42 & -41 & -741 & \\
\hline & & $-0,18 \%$ & $-0,14 \%$ & $-0,12 \%$ & $-0,11 \%$ & $-0,08 \%$ & $-0,07 \%$ & $-0,07 \%$ & $-0,07 \%$ & $-0,06 \%$ & $-0,06 \%$ & $-0,06 \%$ & $-0,06 \%$ & $-1,07 \%$ & -928 \\
\hline \multirow{2}{*}{ Variance } & By & -31 & -24 & -20 & -20 & -13 & -12 & -12 & -12 & -11 & -11 & -11 & -10 & -188 & $-1,34 \%$ \\
\hline & Company & $-0,04 \%$ & $-0,03 \%$ & $-0,03 \%$ & $-0,03 \%$ & $-0,02 \%$ & $-0,02 \%$ & $-0,02 \%$ & $-0,02 \%$ & $-0,02 \%$ & $-0,02 \%$ & $-0,02 \%$ & $-0,01 \%$ & $-0,27 \%$ & \\
\hline \multirow[b]{2}{*}{ Company } & \multirow{2}{*}{ By Market } & 108 & 70 & 398 & 172 & 61 & 103 & 144 & 106 & -99 & -156 & -57 & 29 & 880 & \\
\hline & & $0,16 \%$ & $0,10 \%$ & $0,58 \%$ & $0,25 \%$ & $0,09 \%$ & $0,15 \%$ & $0,21 \%$ & $0,15 \%$ & $-0,14 \%$ & $-0,23 \%$ & $-0,08 \%$ & $0,04 \%$ & $1,27 \%$ & -817 \\
\hline \multirow[t]{2}{*}{ Price Variance } & By & -532 & -77 & 42 & -500 & -259 & -148 & -39 & -151 & -90 & 52 & 59 & -54 & -1.697 & $-1,18 \%$ \\
\hline & Company & $-0,77 \%$ & $-0,11 \%$ & $0,06 \%$ & $-0,72 \%$ & $-0,37 \%$ & $-0,21 \%$ & $-0,06 \%$ & $-0,22 \%$ & $-0,13 \%$ & $0,07 \%$ & $0,08 \%$ & $-0,08 \%$ & $-2,45 \%$ & \\
\hline \multirow{4}{*}{$\begin{array}{l}\text { Company } \\
\text { Turnover } \\
\text { Variance }\end{array}$} & \multirow{2}{*}{ By Market } & -560 & 488 & 511 & -223 & 104 & -48 & 571 & -125 & -175 & 97 & -125 & -229 & 286 & \\
\hline & & $-0,81 \%$ & $0,70 \%$ & $0,74 \%$ & $-0,32 \%$ & $0,15 \%$ & $-0,07 \%$ & $0,82 \%$ & $-0,18 \%$ & $-0,25 \%$ & $0,14 \%$ & $-0,18 \%$ & $-0,33 \%$ & $0,41 \%$ & 1.179 \\
\hline & By & 934 & -458 & 598 & 61 & 170 & 112 & -672 & -220 & 247 & -94 & 215 & 1 & 893 & $1,70 \%$ \\
\hline & Company & $1,35 \%$ & $-0,66 \%$ & $0,86 \%$ & $0,09 \%$ & $0,24 \%$ & $0,16 \%$ & $-0,97 \%$ & $-0,32 \%$ & $0,36 \%$ & $-0,14 \%$ & $0,31 \%$ & $0,00 \%$ & $1,29 \%$ & \\
\hline \multicolumn{2}{|l|}{$\begin{array}{c}\text { CompanyTurn } \\
\text { over }\end{array}$} & 373 & 30 & 1.109 & -162 & 274 & 64 & -101 & -345 & 73 & 3 & 90 & -229 & 1.179 & \\
\hline \multicolumn{2}{|l|}{ Variance } & $0,54 \%$ & $0,04 \%$ & $1,60 \%$ & $-0,23 \%$ & $0,40 \%$ & $0,09 \%$ & $-0,15 \%$ & $-0,50 \%$ & $0,10 \%$ & $0,00 \%$ & $0,13 \%$ & $-0,33 \%$ & $1,70 \%$ & \\
\hline
\end{tabular}

$\mathrm{BP}=$ Brake Pads, $\mathrm{CK}=$ Cluck Kit, $\mathrm{CB}=$ Car Batteries, $\mathrm{DK}=$ Distribution Kit, $\mathrm{BD}=$ Brake Discs, $\mathrm{FF}=$ Fuel Filters, $\mathrm{FW}=\mathrm{Flywheels}$, $\mathrm{SS}=$ Steering and Suspension, $\mathrm{SA}=$ Shock Absorbers, $\mathrm{AS}=$ Alternators and Starters, $\mathrm{AF}=\mathrm{Air}$ Filters and WP=Water Pumps

The bridge graph makes immediately visible the contribution of each determinant to the passage between past and current company turnover (figure 12):

a. if the company has aligned itself with the volumes market trend, turnover would have decreased by -1.090 to reach 68.204; but the company has overperformed for +3.961 and therefore the turnover increased for the volume variance up to $72.165(69.294+3.961-1.090)$, other things being equal: the difference between the actual company turnover, 70.473 , and 72.165 is related to the mix, bonuses and prices determinants;

b. the mix company trend would have reduced the turnover by -1.183 , but the outperformance of the latter, +1.237 , would have led to a turnover equal to 72.219 , bonuses and prices being equal;

c. market bonus variance is negative for -741 in terms of company turnover but also in this case the company has a negative performance for -188 because the higher bonuses granted to customers. The current turnover should 
have been equal to 71.291 : the difference of $-871,70.473-71.291$, is related to the lower actual prices for the company that underperformances for -1.697 .

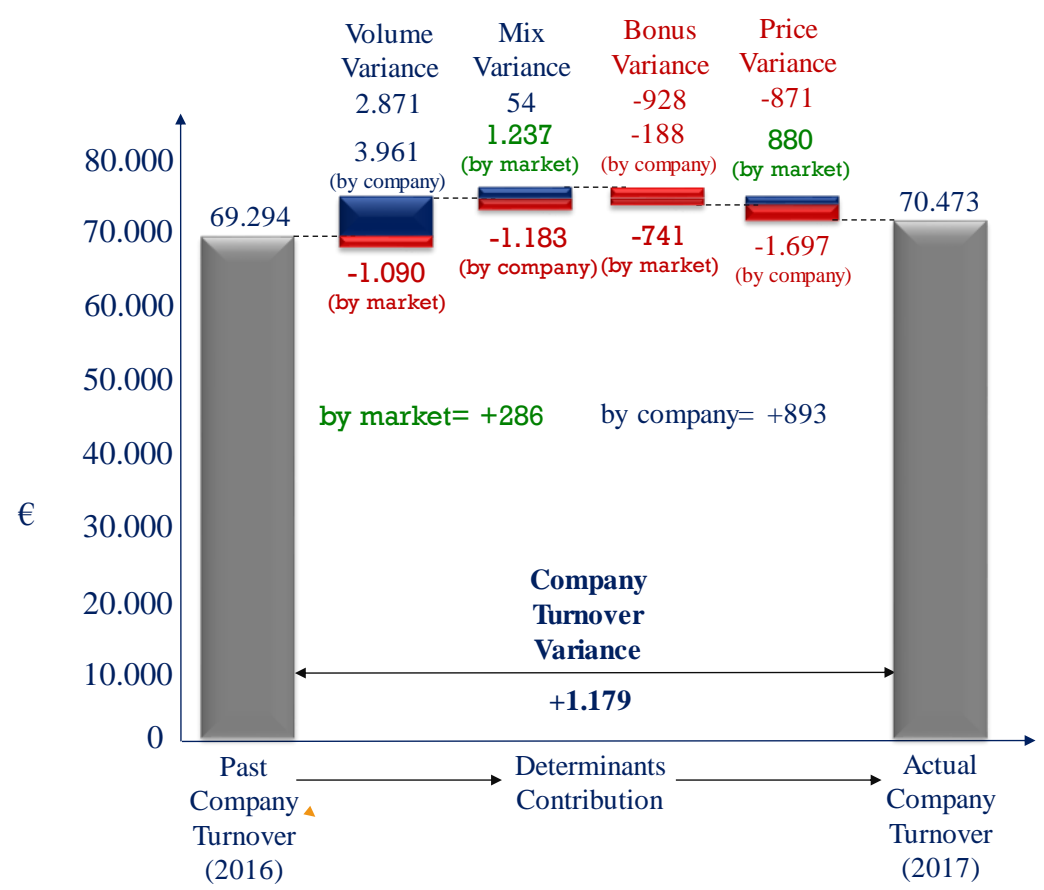

Figure 12. Company turnover variances by market trend and by company performance: the bridge chart

\section{Conclusions}

In brief, the analysis of the turnover variances allows:

1. to investigate the elementary components of the selected result and the relationships between the latter and the causes that determine their evolution;

2. to measure current performance with respect to a double time horizon: towards the final results of the past and towards the results planned for the future, always using the same management alphabet made of volumes, mixes, bonuses, prices, etc., determinants that in turn can refer to different areas of analysis such as customers, product categories, territorial areas, company branches, agents, etc.;

3. to understand in depth the causes of the deviations and to intervene appropriately in terms of actions, resources and competences;

4. to continuously identify the change in the relationships between the elementary components of a result and to adopt the most appropriate operational measures;

5. to measure the managerial performance and to build a more coherent and useful managerial compensation system;

6. to incentivize and improve the learning process both of the company's management dynamics and of the related competitive context and therefore to improve the strategic process in terms of managerial awareness and internal consistency;

7. to complete the planning and management control process by highlighting the critical issues, ordering the latter for relevance and distinguishing managerial priorities in terms of decisions and actions.

As can be seen, the analysis of the turnover variances, as well as other financial and economic variables, is not only a management control tool, but a real path of interdisciplinary managerial development. The skills and evaluations of the marketing \& sales, administration, finance, production, etc. processes are shared with the aim of identifying the management's priorities and creating value for the company as a whole. In this direction, investigating, identifying, measuring, understanding and sharing promptly the dynamics of the determinants of turnover in comparative terms 
between the company and the competitive context constitutes a further essential step to conquer, preserve and strengthen the sources of the competitive advantage.

\section{References}

Anthony, R.N., Hawkins, D.F., \& Merchant, K.A. (1999). Accounting Text and cases, chapters 20 and 21 (10 $0^{\text {th }}$ ed.). McGraw-Hill.

Bubbio, A. (2009). Rivalutazione dell'analisi degli scostamenti: Ricavi e Margini. Controllo di Gestione (n.6).

Damodaran, A. (2018). The Dark Side of Valuation: Valuing Young, Distressed, and Complex Businesses. Pearson Education (US).

Donna, G., \& Riccaboni, A. (2003). Manuale del controllo di gestione. Ipsoa. Collana: Manuali operativi. EAN: 9788821717970.

Gelman, A. (2004). Analysis of Variance. Columbia University.

Gelman, A. (2005). Analysis of variance? Why it is more important than ever. The Annals of Statistics, 33, 1-53. https://doi.org/10.1214/009053604000001048

Guelfi, S. (2013). Mapping of the Strategic Positioning and Sequencing through the Integrated Value Creation Model: The Wholesale Spare Parts Distribution in the Italian Automotive Independent After Market in the 2008-2011 Period. International Journal of Business Administration, 4(4).

Guelfi, S., Norese, M.F., \& Saluto, P. (2016). An integration of theoretical knowledge, day by day experience and multicriteria methods to support the entrepreneurial learning process. Measuring Business Excellence. https://doi.org/10.1108/MBE-12-2015-0056

Hilton, R., Maher, M., \& Selto, F. (2008). Cost Management Strategies for Business Decision. Mcgraw-Hill Irwin, New York, NY.

James, L.G. (2003). Foundations of Economic Value Added (2nd ed.). Wiley Finance.

Kaplan, R.S. (1982). Advanced Management Accounting, chapters 9 and 10. Prentice Hall, Englewood Cliff.

Porter, M.E. (1979, March-April). Competitive Strategy: Techniques for analyzing industries and competitors. New York, The Free Press.

Rappaport, A. (1998). Creating Shareholder Value. The New Standard for Business Performance. New York, The Free Press.

Simons, R. (2013). Performance Measurement and Control Systems for Implementing Strategy Text and Cases: Pearson New. International Edition.

\section{Notes}

Note 1. Revenues are a monetary expression of the degree of the market appreciation of the output generated by the company.

Note 2. The mix analyzed in the present article refers to the basket of products sold, but there may be other interesting changes in the mix compared to, for example, quality, size, location, etc, of customers. As concerns the mix determinant it's very important to distinguish three different effects: mix effect from disused products, mix effect from new products, mix effect from continuing products. These different mix effects will be analyzed in a next article.

Note 3. Bonuses are the only commercial cost considered as they directly impact on net sales while other commercial costs, for example commissions to agents, transport costs, etc., don't contribute to the determination of net sales and will be the subject of a next article.

Note 4. As analyzed in the previous table 6, in relation to the better understanding of the company's turnover performance it is appropriate to normalize, set equal to 100 the company turnover variance, the different contributions of each determinant: distinguishing the effect on turnover corresponding to the market trend from that of the company's differential performance. 